Prepared for the U.S. Department of Energy

under Contract DE-AC05-76RL01830

\title{
Dimming LEDs with Phase-Cut Dimmers: The Specifier's Process for Maximizing Success
}

NJ Miller

ME Poplawski

October 2013 


\title{
DISCLAIMER
}

This report was prepared as an account of work sponsored by an agency of the United States Government. Neither the United States Government nor any agency thereof, nor Battelle Memorial Institute, nor any of their employees, makes any warranty, express or implied, or assumes any legal liability or responsibility for the accuracy, completeness, or usefulness of any information, apparatus, product, or process disclosed, or represents that its use would not infringe privately owned rights. Reference herein to any specific commercial product, process, or service by trade name, trademark, manufacturer, or otherwise does not necessarily constitute or imply its endorsement, recommendation, or favoring by the United States Government or any agency thereof, or Battelle Memorial Institute. The views and opinions of authors expressed herein do not necessarily state or reflect those of the United States Government or any agency thereof.

\author{
PACIFIC NORTHWEST NATIONAL LABORATORY \\ operated by \\ BATTELLE \\ for the \\ UNITED STATES DEPARTMENT OF ENERGY \\ under Contract DE-AC05-76RL01830 \\ Printed in the United States of America \\ Available to DOE and DOE contractors from the \\ Office of Scientific and Technical Information, \\ P.O. Box 62, Oak Ridge, TN 37831-0062; \\ ph: (865) 576-8401 \\ fax: $(865)$ 576-5728 \\ email: reports@adonis.osti.gov \\ Available to the public from the National Technical Information Service \\ 5301 Shawnee Rd., Alexandria, VA 22312 \\ ph: (800) 553-NTIS (6847) \\ email: ordersantis.gov <http://www.ntis.gov/about/form.aspx> \\ Online ordering: http://www.ntis.gov
}

This document was printed on recycled paper.

(8/2010) 


\section{Dimming LEDs with Phase-Cut Dimmers: The Specifier's Process for Maximizing Success}

Final Report prepared in support of the DOE Solid-State Lighting Technology Demonstration GATEWAY Program

Study Participants:

Pacific Northwest National Laboratory

U.S. Department of Energy

NJ Miller

ME Poplawski

October 2013

Prepared for

the U.S. Department of Energy

under Contract

Pacific Northwest National Laboratory

Richland, Washington 99352 
PNNL-22945

\section{Preface}

This document is a report of observations and results obtained from a lighting demonstration project conducted under the U.S. Department of Energy (DOE) GATEWAY Demonstration Program. The program supports demonstrations of high-performance solid-state lighting (SSL) products in order to develop empirical data and experience with in-the-field applications of this advanced lighting technology. The DOE GATEWAY Demonstration Program focuses on providing a source of independent, third-party data for use in decision-making by lighting users and professionals; this data should be considered in combination with other information relevant to the particular site and application under examination. Each GATEWAY Demonstration compares SSL products against the incumbent technologies used in that location. Depending on available information and circumstances, the SSL product may also be compared to alternate lighting technologies. Though products demonstrated in the GATEWAY program may have been prescreened for performance, DOE does not endorse any commercial product or in any way guarantee that users will achieve the same results through use of these products.

\section{Acknowledgements}

The New York State Energy Research and Development Authority (NYSERDA) for several years has recognized the complication of dimming LED sources, and its potential to slow the market adoption of LED technologies. Support for the GATEWAY demonstration project at the Burden Museum was provided by NYSERDA to explore this issue. Jan Moyer Design provided the progressive lighting design for the Burden Museum, coordinating the controls design with the manufacturers, and providing documentation adapted for this report. The initial dimming compatibility evaluation on the Burden Museum was assisted by Jim Yorgey of Lutron Electronics, who contributed invaluable experience. James Hundt of Foresight Architects generously provided the information on the Hudson River Valley church example. Patricia Glasow of Auerbach Glasow French, Architectural Lighting Design and Consulting introduced the need for this document, and provided a review when it was in a very early draft state. Jeremy Yon of Litecontrol provided a technical review of an intermediate draft. Ethan Biery of Lutron Electronics collaborated on the development of some of the technical background material. The authors would like to thank these individuals for their valuable contributions. 
PNNL-22945

\section{Executive Summary}

Solid-state lighting now has a proven record for delivering equivalent lighting performance with improved energy efficiency compared to most halogen, compact fluorescent, and high-intensity discharge lighting systems. Yet a significant barrier to market adoption has been its often-poor performance with existing dimming control systems. Although some light-emitting diode (LED) light sources dim as smoothly as do incandescent lamps, others can exhibit erratic dimming behavior; dim to a level that is unacceptably high; or not dim at all.

There are several dimming techniques in the lighting industry, including Digital Addressable Lighting Interface (DALI), 0-10V, DMX, and other techniques that separate the communication of the dimming level to the light source from the AC mains voltage provided to the light source. However, the majority of the installed base of dimming systems use phase-control techniques to dim incandescent lamps. This report reviews how phase-cut dimmers work, how LEDs differ from the incandescent lamps that these dimmers were historically designed to control, and how these differences can lead to complications when trying to dim LEDs. The issues are often ones of LED source and phase-cut dimmer compatibility, rather than a shortcoming in the LED source itself. Compatibility between a specific LED source and a specific phase-cut dimmer is often unknown and difficult to assess, and ensuring compatibility adds complexity to the design, specification, bidding, and construction observation phases for new buildings and major remodel projects. In existing buildings, where LED lamps are replacing installed incandescent/halogen lamps for energy savings and longer life, it is necessary to determine whether a specific make and model of LED lamp will meet expectations when controlled by the installed dimming system(s).

This report provides both general guidance and step-by-step procedures for designing phasecontrolled LED dimming on both new and existing projects, as well as real-world examples of how to use those procedures. The general guidance aims to reduce the chance of experiencing compatibility-related problems, and if possible, ensure good dimming performance. Compatibility alone does not guarantee dimming quality characteristics such as lack of flicker, smoothness, or a specific minimum dimmed level. These characteristics are best evaluated by observation, which is why mockups are so strongly recommended.

This guidance is summarized below in rough order of decreasing confidence:

- Perform a full mockup of every lighting circuit, including all LED sources and dimming controls, and test over the full dimming range. This provides the best, first-hand experience of how the final installation will perform.

- If a mockup is not possible, use a proven combination of LED sources and dimmer. The recommendation may come from the specifier's own previous experience, or that of a trusted colleague, but the information should not be more than six months old, or the source or dimmer characteristics may have changed.

- For wall-box installations, specify a National Electrical Manufacturers Association (NEMA) SSL-7A-compliant dimmer along with compliant LED sources. This pairing of compliant products guarantees a level of compatibility and ensures the dimmer will not negate the dimming claims of the lamp or luminaire.

- Specify a combination of LED sources and dimming control recommended by the LED source or dimming control manufacturer, or ideally both. The real-world examples included in the report 
PNNL-22945

make extensive use of manufacturer's dimming compatibility data for LED products. The acceptability of the LED source performance in this case is purely based on manufacturer's judgment of the dimming quality.

- Specify a 3-wire dimmer (which all architectural dimming systems are, but not all wall-box dimmers), and derate the capacity of the dimmer. This eliminates most dimmer-caused compatibility issues, allowing the LED source to perform to its potential. It does not ensure good quality dimming, however, because that is limited by the inherent capabilities of the LED source.

- Specify a phase-control type (e.g., forward-phase, or reverse-phase) recommended by the LED source manufacturer, and derate the capacity of the dimmer. This should eliminate some dimmercaused compatibility issues. Again, the acceptability of the LED source performance in this case is purely based on manufacturer judgment of the dimming quality.

The step-by-step procedures describe the type of product research that can be done by the specifier to improve the odds of achieving good dimming performance. This research and documentation must be performed for every dimmed load on a project. It is not a simple undertaking: specifiers should be prepared to spend considerable time and effort in this task.

Two step-by-step real-world examples are provided to guide the specifier in checking for and documenting compatibility when using phase-control dimming. One example is the Burden Museum in Troy, N.Y., a GATEWAY demonstration project in construction phase at the time of this writing, and another is a church in the Hudson River valley in New York where the congregation was looking for guidance in selecting LED replacement lamps for their worship space.

Specifiers should consider alternatives to phase-control dimming for LED sources, such as DALI or even wireless approaches. These also have their positive and negative attributes, and varying (typically higher) costs, but the use of approaches that separate the control signal from the AC mains voltage to the LED source may result in higher levels of performance, more predictability, and fewer headaches. 



\section{Acronyms and Abbreviations}

$\begin{array}{ll}\text { DALI } & \text { Digital Addressable Lighting Interface } \\ \text { DMX } & \text { Digital MultipleX } \\ \text { DOE } & \text { U.S. Department of Energy } \\ \text { ELV } & \text { electronic low voltage } \\ \text { HIR } & \text { halogen infrared } \\ \text { INC } & \text { incandescent } \\ \text { LED } & \text { light-emitting diode } \\ \text { MLV } & \text { magnetic low voltage } \\ \text { MR } & \text { multi-faceted reflector } \\ \text { NEMA } & \text { National Electrical Manufacturers Association } \\ \text { PAR } & \text { parabolic aluminized reflector } \\ \text { PHPM-PA } & \text { phase-adaptive power module } \\ \text { PNNL } & \text { Pacific Northwest National Laboratory } \\ \text { PSC } & \text { preset scene controller } \\ \text { RMS } & \text { root mean square } \\ \text { SSL } & \text { solid-state lighting }\end{array}$





\section{Contents}

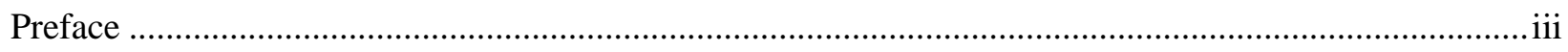

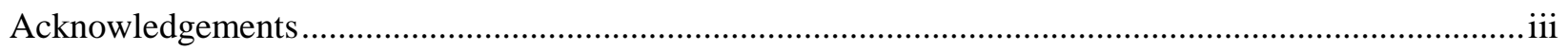

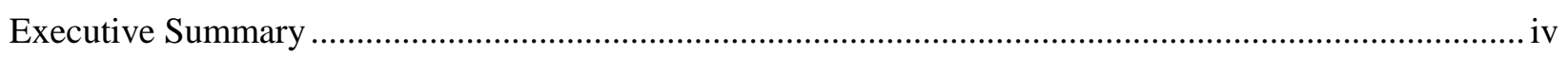

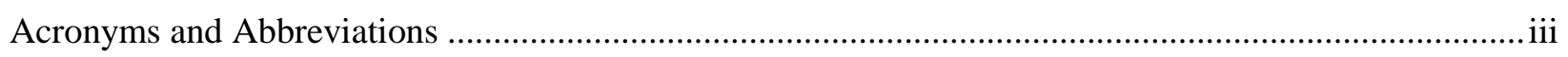

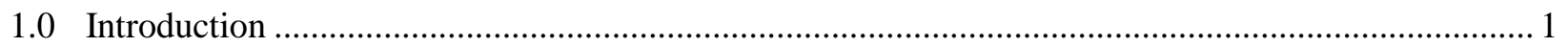

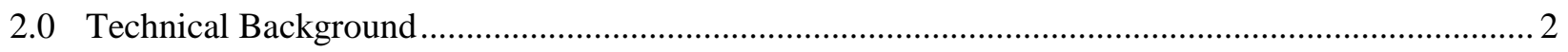

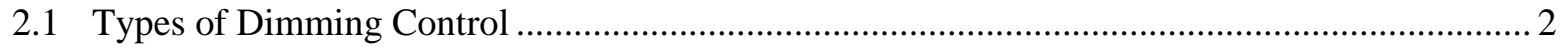

2.2 Phase-Control .......................................................................................................... 2

2.2.1 Forward Phase-Control ….......................................................................................... 3

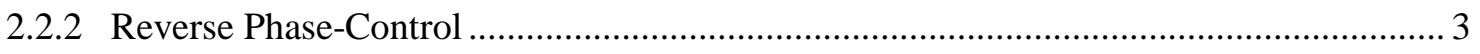

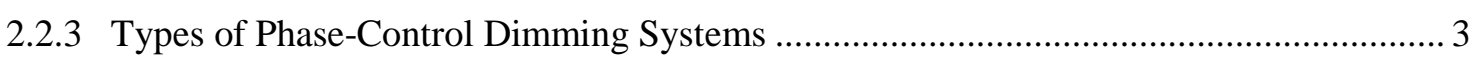

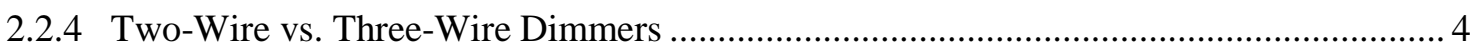

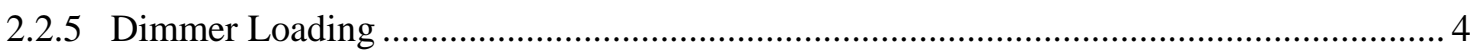

2.3 How LED Sources Differ from Incandescent …...................................................................... 5

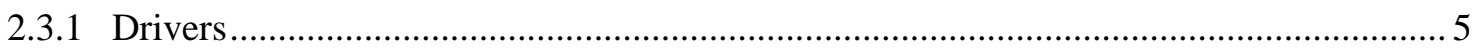

2.3.2 Repetitive Peak Currents and Effective Dimmer Loading ............................................ 5

2.3.3 Interaction with Two-Wire Dimmers .......................................................................... 7

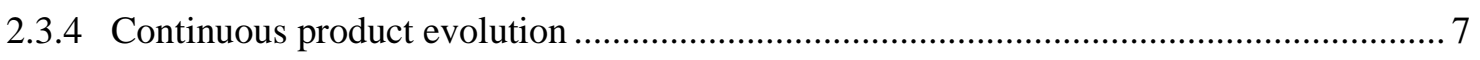

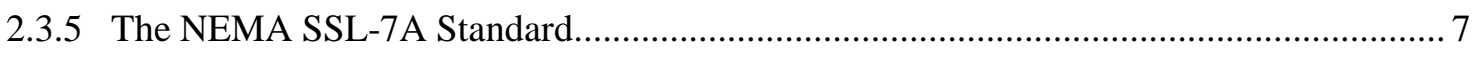

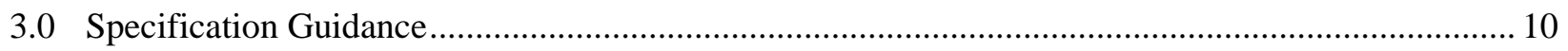

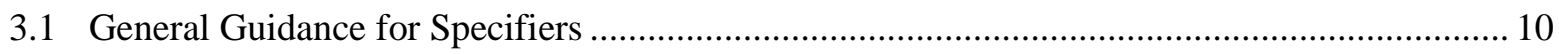

3.1.1 Set Proper Dimming Expectations ......................................................................... 10

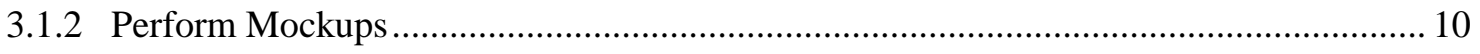

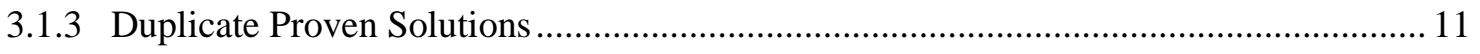

3.1.4 Specify 3-Wire or NEMA SSL-7A Dimmers for Wall-Box Applications....................... 11

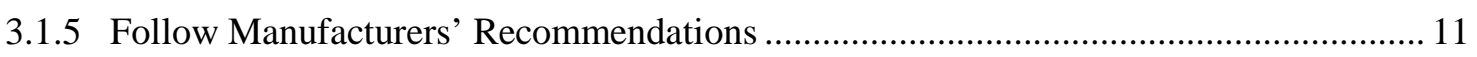

3.2 Step-by-Step Guidance for New Construction or Major Remodel Projects.............................. 12

3.3 Step-by-Step Guidance for Existing Projects ....................................................................... 13

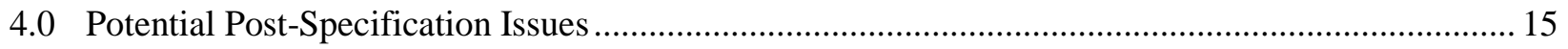

4.1 Mixing Multiple Light Sources ..................................................................................... 15

4.2 The Effect of Time, Change, and Substitutions ................................................................... 15

5.0 New Construction or Major Remodel Project Example: Burden Museum ....................................... 16

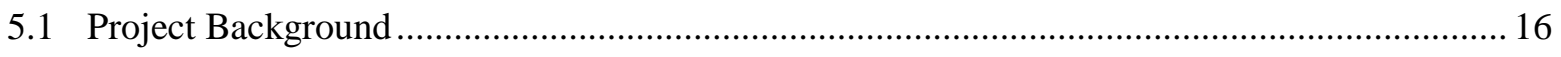

5.2 Example Controls Design and Specification Process........................................................... 17 


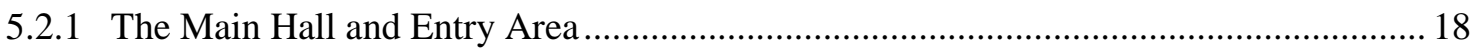

5.2.2 Storage/Collection Area, with Wall-Box Controller and Conflicting Information .......... 21

6.0 Existing Project Example: Hudson River Valley Church............................................................. 1

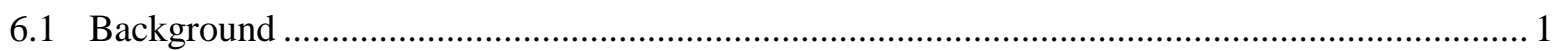

6.2 Suggested Approach to Resolving the Issue of Smooth Dimming at the Church....................... 3

6.3 Example Controls Design and Specification Process.................................................................. 3

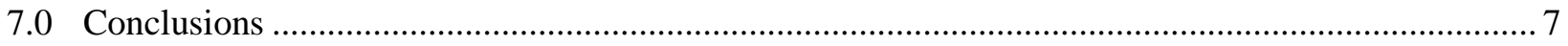

Appendix A : Burden Museum Main Room Lighting Plan ...................................................................... A.1

Appendix B : Burden Museum Main Room Track Lighting Plan .........................................................1

Appendix C : Burden Museum Interior Luminaire Schedule for the Main Hall and Entry Hall...............C.1

Appendix D : Burden Museum Interior Luminaire Schedule for the Collection/Storage Room.............. D.1

Appendix E : Burden Museum Dimming Compatibility Documents ........................................................ 1

Appendix F : Burden Museum Storage Area Vault Dimming Documents..............................................F.1

Appendix G : Hudson River valley church dimming documents ......................................................... G.1

\section{Figures}

Figure 1. The effect of phase-control on an incandescent light source..................................................... 2

Figure 2. Forward-phase, or leading edge waveform modification (left) vs. reverse-phase, or trailing edge waveform modification (right).

Figure 3. Comparison of typical LED (red line) compared to incandescent (blue line) repetitive peak currents..

Figure 4. NEMA SSL-7A dimmer and LED Light Engine (LLE) classifications.................................... 9

Figure 5. The Burden Museum, Troy, NY. (Photo courtesy The Hudson Mohawk Industrial Gateway.)..... 16

Figure 6. Computer-rendered visualization of the completed interior. (Photo courtesy George Gruel, Oddstick Studio.)

Figure 7. Section of dimming schedule for Main Hall and Entry Hall, showing track lighting zones.

Figure 8. View of altar and platform area, lighted with PAR38 track heads. (Foresight Architects, Schenectady N.Y.; Randall Perry Photography, Schaghticoke, N.Y.)

Figure 9. View of Hudson River valley worship space, showing track mounted to beams with MR16 track heads aimed downward into pews. (Foresight Architects, Schenectady N.Y.; Randall Perry Photography, Schaghticoke N.Y.) 


\subsection{Introduction}

The U.S. Department of Energy (DOE) Solid-State Lighting (SSL) GATEWAY program has been monitoring installations of light-emitting diode (LED) products for several years, including many installed with dimming controls. The dimming performance in these installations has varied widely. Some LED dimming has been excellent, almost indistinguishable from the performance of halogen lamps or the performance of fluorescent lamps on electronic dimming ballasts, but GATEWAY has also encountered LED products that

- do not illuminate at all

- do not dim at all

- dim erratically (e.g., abruptly, not smoothly)

- exhibit a limited dimming range, often turning off long before a comparable halogen lamp would extinguish

- shift undesirably in color as they dim

- remain on, or flash erratically when they are supposed to be off

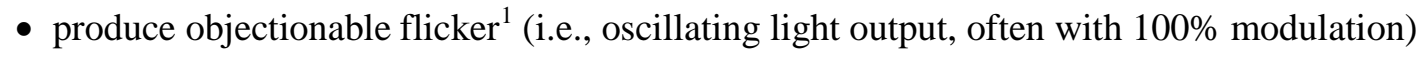

- produce audible noise.

This report is aimed at helping specifiers achieve the LED dimming required for their projects, based on experience from CALiPER ${ }^{2}$ testing and GATEWAY demonstration projects. It is focused on the most common dimming application: the use of phase-control to dim integral lamps and dedicated LED luminaires. It contains a technical review of phase-control dimming provided as background in Section 2.0, along with common LED source compatibility issues that can lead to poor performance, and industry activities that may address those issues as the market evolves. Section 3.0 provides general guidelines and recommended procedures, as well as examples of both.

Recommended procedures are provided for both new construction and major remodel projects, and for existing installations. Examples for applying these procedures are provided for two projects:

- an in-progress GATEWAY project where LEDs and a new lighting control system are being specified for use in the Burden Museum in Troy, N.Y.

- a project where halogen MR16 and PAR38 halogen lamps controlled by an architectural dimming system are being retrofitted with LED lamps at a church in the Hudson River valley, N.Y.

These projects are both in construction, so project performance results are not yet available. However, both are useful as real-life illustrations of the process for evaluating LED lighting products in conjunction with phase-cut dimmers.

\footnotetext{
${ }^{1}$ http://apps1.eere.energy.gov/buildings/publications/pdfs/ssl/flicker_fact-sheet.pdf

${ }^{2}$ DOE Commercially Available LED Product Evaluation and Reporting Program, http://www1.eere.energy.gov/ buildings/ssl/caliper.html.
} 


\subsection{Technical Background}

\subsection{Types of Dimming Control}

There are many approaches to dimming of LED systems, including the use of phase-control dimmers originally developed for incandescent lamps, and dimmers designed for fluorescent and high-intensity discharge (HID) lamps. Dimmers using Digital Addressable Lighting Interface (DALI), 0-10V, or other approaches to control fluorescent loads all require additional wires to communicate the desired dimmed lighting level to the luminaire, separately from the wires that power the luminaire. These additional control wire(s) add complexity and cost, especially in retrofit installations. However, they also offer much more consistent control of the fluorescent or HID source, and in some cases allow luminaires to communicate back to the control system. While these approaches are being used to dim LED products with some success, and may be discussed in detail in future GATEWAY efforts, this report focuses on phase-control approaches, which are most commonly used in the lighting industry today.

\subsection{Phase-Control}

Phase-control devices, commonly referred to as phase-cut dimmers, were developed in the 1960s as a means for safely and cost-effectively dimming incandescent sources, which behave electrically like a resistor once they have reached a steady operating temperature. These dimmers alter the output of light sources by modifying the waveform of the AC mains voltage that powers the sources. This modification effectively combines the lighting control signal with the input power signal, as opposed to delivering the control signal to the light source separately. Phase-cut dimmers impart this modification by "cutting” or removing some portion of the sinusoidal waveform phase, which reduces the root-mean-square (RMS) voltage of the waveform. ${ }^{1}$

The power drawn by an incandescent or halogen lamp typically has a near-linear relationship with the RMS value of its input voltage waveform. For example, a light source that draws $60 \mathrm{~W}$ when powered by 120 Vrms will only draw somewhere in the vicinity of 20-25W when the AC waveform has been altered to yield 60Vrms. Since incandescent sources lose efficacy dramatically as they are dimmed, the reduction in light output is much more significant. The same $60 \mathrm{~W}$ source that outputs 800 lumens when powered by 120 Vrms will only generate about 40-50 lumens when the AC waveform has been altered to yield 60 Vrms (Figure 1).

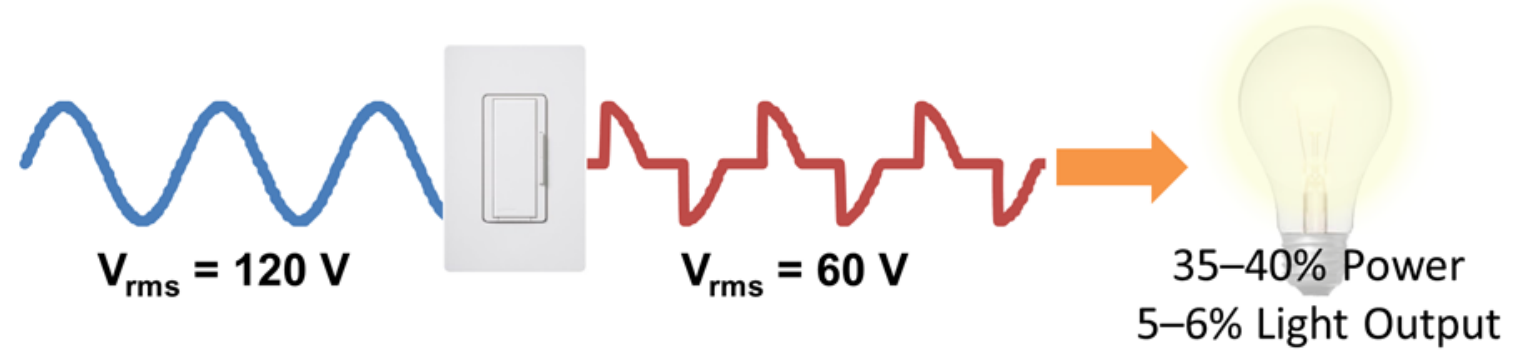

Figure 1. The effect of phase-control on an incandescent light source.

\footnotetext{
${ }^{1}$ The RMS value of a voltage waveform is a measure of the average signal seen by a resistive load.
} 


\subsubsection{Forward Phase-Control}

There are many varieties of phase-control devices, and they go by many names. Forward phasecontrol devices, also called "forward phase-cut”, “TRIAC”, "leading edge,” or "INC” (for incandescent) dimmers, reduce the RMS voltage delivered to the lamp by removing a portion of the AC waveform from the forward phase, or leading edge, as shown in Figure 2 (left). A small patch is cut for slight dimming; more is cut for deeper dimming.

Magnetic low voltage (MLV) dimmers, which were originally designed for use with magnetic transformers, also use the forward phase-control approach. However, they contain additional electronics to ensure that they do not induce DC currents that could overheat the transformer or the dimmer, thereby leading to premature failure.

\subsubsection{Reverse Phase-Control}

Reverse phase-control devices, also called "reverse phase-cut," “electronic low voltage” (ELV), or "trailing edge" dimmers, remove a portion of the AC waveform from the reverse phase, or trailing edge (See Figure 2, right). They were originally designed to improve the performance of low-voltage halogen lamps operating on electronic transformers.
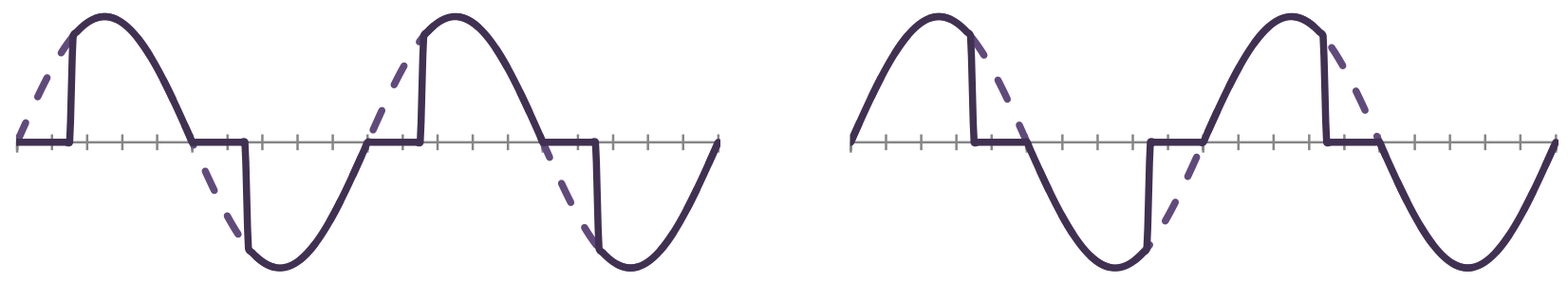

Figure 2. Forward-phase, or leading edge waveform modification (left) vs. reverse-phase, or trailing edge waveform modification (right).

\subsubsection{Types of Phase-Control Dimming Systems}

Phase-control dimming systems can range from a single wall-box device controlling one group of lights in a room, to room-size multi-scene preset systems that control multiple groups of lights, to multiroom (or even building-level) architectural dimming systems. Wall-box dimmers are generally smaller in size and load capacity than multi-scene or architectural systems, and are typically capable of controlling just one load type (e.g., they cannot be switched in the field from an incandescent load type to an electronic low-voltage load type). More sophisticated or larger dimming systems may have fieldselectable load type, or even the ability to sense the connected load type and automatically switch to the most suitable dimming control mode. Some wall-box and architectural dimmers can be modified with an interface device that either replicates an input dimming signal on the output of a second, higher-capacity dimming control device, thereby expanding the load size a dimmer can handle, or translates it into a 
different dimming signal that is more suitable for a different load type. Larger systems can usually accommodate these interfaces more easily than a wall-box dimmer.

\subsubsection{Two-Wire vs. Three-Wire Dimmers}

Most simple wall-box phase-cut dimmers require only two connections (in addition to electrical ground): one for the input, often referred to as the "line" or "hot" wire connection, and one for the output, also referred to as the "load" or "dimmed hot" wire connection. Such "two-wire" dimmers are direct replacements for switches found in wall-boxes. The line wire is connected to the AC mains voltage, and supplies power to both the dimmer and the light source load(s). The load wire, which carries the dimmed (phase-cut) voltage, supplies power only to the light source loads. Most loads on an AC electrical circuit, including all light sources, are connected between an input voltage line and a neutral line, which provides an electrical return path for power delivered to the load. Switches and two-wire dimmers are exceptions, in that they are connected between an input voltage (source) and output voltage (source), rather than between an input voltage (source) and neutral (return). This configuration, which effectively places the dimmer in series with the lighting load, makes it more challenging to power any internal circuitry in the dimmer and stay synchronized with the input AC waveform. When the dimmer is on, it can only draw power for its internal circuitry during the phase-cut portion of the voltage waveform. While basic dimmer circuitry does not require much power, it can be difficult for two-wire dimmers to provide enough power for advanced features (e.g., night lights, light level indicators, or wireless features). When the dimmer is off, the series configuration poses a complication for dimmers that still have internal circuitry that needs to be powered. Since the only path for current flow is through the load, the dimmer circuitry has to obtain the power it needs without causing the lighting loads to turn on. For incandescent sources, this is fairly simple because the amount of current flowing through the lighting load is not enough to cause the filament to glow.

Three-wire dimmers require a third connection to a neutral (typically white) wire. The presence of this electrical return path makes it much easier for the dimmer to power its internal circuitry and stay synchronized with the input AC waveform. The three-wire configuration is preferred for higher performance wall-box dimmers, as well as dimmers with advanced features. In the U.S., bringing a neutral wire to wall-boxes is now required in almost all new and remodel construction. As a result, the use of three-wire wall-box dimmers is becoming more common. Architectural dimming systems also require a neutral connection.

\subsubsection{Dimmer Loading}

All phase-cut dimmers have a minimum and maximum load "rating," which specifies the lighting load range (in watts, historically) over which the manufacturer claims the device will operate as intended while living up to its lifetime and warranty claims. Minimum ratings are determined by evaluating the minimum dimmer circuit requirements for normal operation, while maximum ratings are determined by evaluating the increased stress on the dimmer as lighting loads are added. The minimum load for most installed phase-control equipment is typically around 40W, while the maximum load varies from $600 \mathrm{~W}$ for wall-box dimmers, to $1000 \mathrm{~W}$ or even 2000W for larger systems. 


\subsection{How LED Sources Differ from Incandescent}

\subsubsection{Drivers}

LED sources differ from their incandescent counterparts in a number of ways. While incandescent sources can be operated directly from AC mains voltage, most LED sources require a "driver", which is somewhat (but not entirely) similar to the ballast required by fluorescent and other sources. The LED driver, which may be integral to the light source as in most retrofit products, or housed in a separate enclosure, carefully controls the current delivered to the LED emitters. Whether separate or integral, the driver electronics determine the dimming performance of an LED source. When the manufacturer of an LED PAR38 lamp claims dimmability and a minimum dimming level of $10 \%$, for example, the manufacturer is actually claiming that the driver built into the lamp can receive a dimmed signal from a specific type of dimming device and in turn reduce the output of the LED emitters within the lamp down to $10 \%$ of the full power level.

For LED sources dimmed using phase-control, however, these claims more accurately describe "potential" dimming performance. Actual dimming performance often depends on the choice of phase-cut dimmer. The cause of this dependency is compatibility between the LED sources and dimmer, rather than the capability of either. Incandescent sources do not vary in ways that affect their behavior with phase-cut dimmers, so its dimming performance is predominantly determined by the dimmer characteristics. In contrast, LED driver circuitry can vary in ways that lead to varying performance with different phase-cut dimmers. Additional compatibility issues are briefly reviewed in the following sections.

\subsubsection{Repetitive Peak Currents and Effective Dimmer Loading}

The average power draw of an electrical load connected to AC mains voltage source can be calculated as the product of the RMS voltage, the RMS current, and the load power factor. Incandescent sources draw a sinusoidal load current that is in phase with the input voltage. As a result, they have a load power factor of one ${ }^{1}$, and the relationship between power (in watts) and RMS current is direct and simple. LED drivers are fundamentally power converters; they draw power from the connected AC mains, and convert it to a form suitable for the LED emitters they power. There are myriad ways to construct an LED driver circuit. One varying characteristic is the method used to draw power from the AC mains. Depending on the method used, LED sources can draw repetitive peak currents that are significantly higher than their incandescent counterparts, as conceptually shown in Figure 3. It is important to differentiate repetitive peak currents, which occur every sinusoidal half cycle (120 times a second for $60 \mathrm{~Hz}$ electrical systems) from inrush peak currents, which occur once, when power is first applied to an electrical system. LED sources commonly have repetitive peak currents that are 5-10x higher than their RMS current draw, with some products exhibiting much higher ratios. Higher repetitive peak currents are more common for LED sources with integral drivers (e.g., retrofit products) and low power factor LED products. While high repetitive peak currents can be a major cause of audible noise in light sources and phase-cut dimmers and radio-frequency interference (RFI) with other electronics, their most significant impact is typically the increased effective loading they present to phase-cut dimmers, compared to the current drawn by incandescent sources.

\footnotetext{
${ }^{1}$ To first order, power factor (which is measured on a scale of 0-1) is a measure of how far a load strays from behaving resistively.
} 
Phase-cut dimmers have historically been rated for minimum and maximum loads based on the wattage of the connected light sources. Maximum load ratings are based on the stress the load puts on electronic components in the dimmer under normal operations. Component stress is dependent on a number of things, including the magnitude and waveform shape of the current flowing through it. The maximum load rating of a phase-cut dimmer controlling incandescent sources is based on the average current magnitude, or the power draw of the connected load. However, LED source drivers have varying power factor performance and do not all draw similar input current waveforms, so neither LED source wattage nor average current magnitude are good proxies for the stress they put on the dimmer. Therefore, the maximum load ratings commonly assigned to phase-cut dimmers based on the wattage of incandescent sources is not valid when LED sources are connected. The net result is that the maximum LED load rating for a particular phase-cut dimmer will be different for different LED sources, and is not easily determined from any commonly measured metric, like input power (in watts) or even repetitive peak current level.

While it is not possible to accurately rate phase-cut dimmers for maximum LED loads without the development of a new metric that characterizes the stress they put on dimmer components, ratings can still be generated according to worst-case assumptions. Some phase-cut dimmer manufacturers have started to generate wattage-based LED-specific maximum load ratings for their new products, based on an assumption of worst-case LED source behavior. Since repetitive peak currents drawn by LED sources result in more dimmer component stress than an incandescent source with the same current draw, LEDspecific maximum load ratings are typically lower than incandescent based ratings. Some commercially available wall-box products have been de-rated by an order of 3-4x; for example, a phase-cut dimmer designed for both incandescent and LED sources may have a maximum load rating of 600W for an incandescent (only) load, and a rating of 150W (600/4) for an LED (only) load. Some LED lamp manufacturers provide guidance on the maximum number of lamps that should be put on a phase-cut dimmer, either for specific dimmers, or based on some assumption of worst-case wall-box dimmer behavior. For example, a lamp manufacturer may advise putting no more than 8 of their 7W LED lamps on a circuit controlled by an incandescent dimmer rated for $600 \mathrm{~W}$, thereby de-rating the dimmer by about a factor of $10(600 / 56)$.

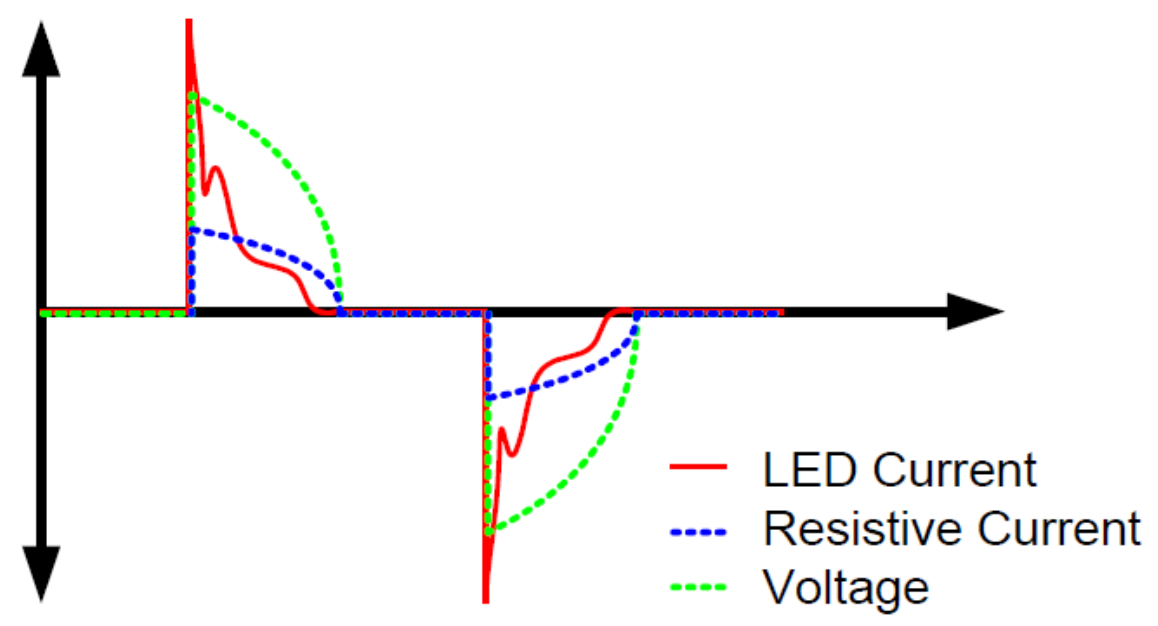

Figure 3. Comparison of typical LED (red line) compared to incandescent (blue line) repetitive peak currents. 


\subsubsection{Interaction with Two-Wire Dimmers}

Three-wire phase-control dimmers generally support advanced features and perform over a wide range of external conditions better than their two-wire counterparts, due to the presence of a neutral wire connection. LED sources amplify the challenges that two-wire dimmers must overcome. LED loads can create series impedances which appear significantly different from the familiar resistive incandescent behavior, leading to erratic dimming performance. This can also effectively limit the maximum number of LED sources that should be used on the dimmer.

LED loads in the off state may not pass enough current to maintain proper operation of the dimmer. This is most problematic for dimmers with advanced features, and can lead to dimmer malfunction or even inoperability. Some LED loads in the off state can accept low levels of current, but behave undesirably at higher levels. In some instances, the LED driver may initiate operation that it cannot sustain, leading to strobing or erratic flashing behavior. Or, the LED driver may actually initiate and maintain a low-level of operation, leading to "ghosting", or the appearance of being on when it is supposed to be off. Finally, some LED loads do not draw enough current over the duration of each halfcycle to keep some two-wire dimmer circuit elements functioning properly, again leading to erratic behavior. While this issue was significant in the early days of LEDs, it has been largely addressed in the market; newer dimmers can operate at lower currents, and newer LED sources can avoid erratic behavior by drawing extra current at critical timing points, sometimes at the expense of LED source efficacy.

\subsubsection{Continuous product evolution}

LEDs are still relatively new to the architectural lighting market, and innovation is still occurring at all LED component levels. Product evolution is rapid and product generation life is short. Newer products with more sophisticated LED drivers typically perform better with a wider range of older dimmers. This continuous evolution can lead to its own problems, however. For example, an older generation LED source may only work well with a small number of ELV dimmers, while a newer model works well with a larger number of forward-phase dimmers, but no longer works well with ELV dimmers.

\subsubsection{The NEMA SSL-7A Standard}

A number of challenges must be overcome to successfully dim LEDs with phase-cut dimmers, especially with two-wire configurations. The installed base of phase-cut dimmers in the U.S. is too varied to be easily characterized, so it is a considerable challenge for an LED source manufacturer to design a driver that works well with all these devices. Recognizing this as a growing barrier to LED adoption, NEMA members decided that the best way to ensure some level of predictable LED source performance would be to effectively reduce the variation over which LED sources and phase-cut dimmers must operate, and put limits on some design variables that can lead to undesirable behavior. In late 2011, NEMA formed the SSL-7 committee, which led to the 2013 publication of SSL-7A, "Phase Cut Dimming for Solid State Lighting: Basic Compatibility". NEMA SSL-7A contains a set of design specifications that aims to ensure that one or more compliant LED sources (or, more specifically, LED light engines) will work well with compliant dimmers. LED Light Engines (referred to in the specification as LLEs) are defined as a combination of one or more LED modules and LED control gear (integral or remote) designed for an AC mains circuit connection (i.e. one or more LED modules and a driver). LLEs describe a wide range of lighting products, from screw-in integrated lamps to luminaires containing separate LED 
drivers, but notably exclude low-voltage sources that do not connect directly to AC mains. The combination of a low-voltage source and a step-down transformer, however, may comprise an LLE.

NEMA SSL-7A contains design specifications for both LLE's and forward-phase two-wire dimmers, as well as tests for determining product compliance with those specifications, which address many of the challenges. It is important to note, however, that NEMA SSL-7A is forward-looking, and intended to be used to design and qualify dimmer and LLE products for use with each other. It is not intended to be used to determine compatibility with existing (non-compliant) products, so the compliance of a dimmer or LLE with SSL-7A does not predict performance with non-compliant products.

An LED light engine or forward-phase dimmer can be deemed SSL-7A compliant if two conditions are met:

- the reliability of the LED light engine and the dimmer are not affected by combining them

- the LED light engine and dimmer meet or exceed the design requirements specified in SSL-7A, as verified by performing the compliance testing described in the standard.

Compliant dimmers will have maximum load ratings, in watts, based on the worst-case LED source behavior allowed by the SSL-7A specification. While SSL-7A should make it easier to determine the maximum lighting load that can be connected to a compliant dimmer, avoid the undesirable behavior that can result from LED source interaction with two-wire dimmers, and predict the minimum dimmed level achievable independent of dimmer make and model, it does not address every potential source of performance variation. A companion document, SSL-7B, may be developed to address things not covered by SSL-7A, such as the shape of the dimming curve.

There are two levels of performance compliance. Type 1 dimmers can be used with any LLE type, and are thus referred to as "universal dimmers" (Figure 4). Type 2 dimmers require additional power for their internal circuitry, and must be paired with LLE's that can support these demands in their off state. Type 2 LLE's can be used with both Type 1 and Type 2 dimmers, and are similarly referred to as "universal”. While a single Type 1 LLE cannot support the off-state power requirements of a Type 2 dimmer, compliant behavior may be obtained by connecting multiple Type 1 LLE’s. 


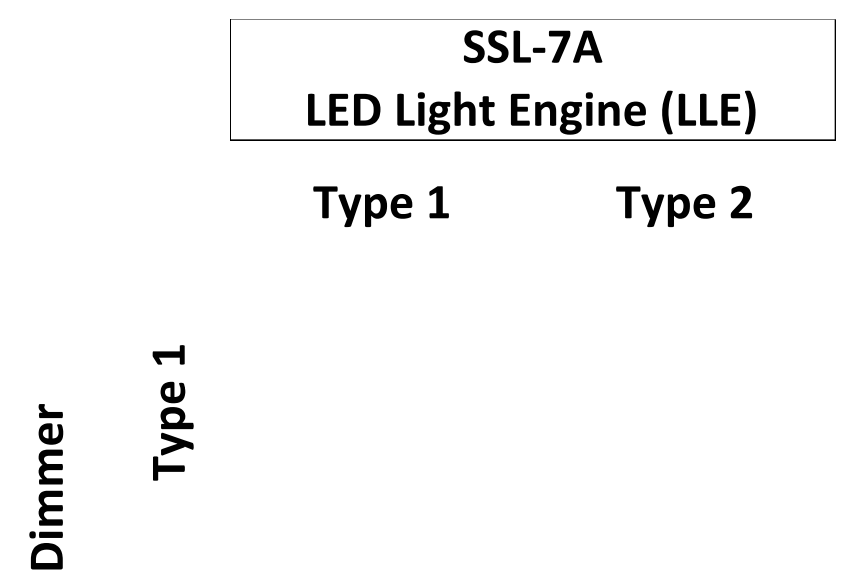

Figure 4. NEMA SSL-7A dimmer and LED Light Engine (LLE) classifications. 


\subsection{Specification Guidance}

This section provides guidance for selecting LED products and dimmers that increases the chances of satisfactory dimming performance. The extra up-front work for the designer/engineer will pay back in reduced problems in the field, fewer product returns and exchanges, and greater client satisfaction with their energy-efficient dimmable LED lighting systems. Following this guidance requires additional design and construction phase time for the specifier and project owner to research the products, perhaps perform full-scale mockups, and diligently check for product evolution during design and construction phases. Additional scrutiny of product substitutions is also warranted, because a change to either a specified LED source or dimmer may affect compatibility, alter the size of the load that can be dimmed, or lead to unsatisfactory performance.

\subsection{General Guidance for Specifiers}

\subsubsection{Set Proper Dimming Expectations}

While there is no industry standard definition for "dimmable," the expectation for many is based on their experience of incandescent performance. With even moderate quality dimmers, incandescent lamps dim smoothly down to levels well below $1 \%$ of nominal light output. At this time, only LEDs with very sophisticated dimming drivers carefully coordinated with specific phase-cut dimmers will deliver similar performance. Unfortunately, today’s LED manufacturer claims of “dimmable” do not consistently describe the range or quality of the dimming. Many manufacturers provide little in the way of claimed performance, not even mentioning potential minimum light level.

Designers and engineers should be diligent in trying to obtain specific performance information from LED product manufacturers, while remembering that most claims describe only potential performance. Actual performance with a phase-cut dimmer is often dependent on the specific dimmer make and model. Nevertheless, if the lamp or driver was only designed to dim to $20 \%$, the specifier should not expect it to do better than that. To some extent, it is important to reduce client expectations of dimming performance with LEDs unless significant design effort and expense go into the designed systems.

\subsubsection{Perform Mockups}

To ensure the highest chance of success, mockups are often essential, especially when there is little or no firm dimming guidance from the LED product or dimmer manufacturer.

- For new installations, specifiers should procure enough of the specific LED lamps or luminaires to simulate the expected maximum and minimum loading of a circuit controlled by each selected dimmer. With the specific dimmer controlling the circuit, the levels should be raised and lowered. The performance of the LED sources should be evaluated over the entire dimming range to see if the requirements for smoothness of dimming, minimum levels of dimming, etc. can be met. If there is unacceptable behavior, switch the dimmer to a different load type (e.g., ELV), if available, and test the dimming performance again. 
- For existing lighting circuits, specifiers should procure enough of the specific LED lamps or luminaires to fill every socket used on each unique dimmer control zone. Evaluate the performance of the installed LED sources over the entire dimming range to see if the requirements for smoothness of dimming, minimum levels of dimming, etc. can be met. If there is unacceptable behavior, see if the dimmer can be switched to a different load type (e.g., ELV), and test the dimming performance again. On-site experimentation with multiple makes and models of LED lamps or luminaires may be the best way to find a product that will deliver the desired performance. There is a low chance of damaging the installed dimmer (or the LED product) in the short time that this testing occurs.

\subsubsection{Duplicate Proven Solutions}

Experience is valuable. A specifier who has had a successful installation with a specific set of LED sources and dimmer(s) within the past several months can justify expressing some level of confidence that the same combination will work equally well on the next project. Colleagues, manufacturers' representatives, and other trusted specifiers can also be sources of reliable information. It is wise to be aware of or ask about any production changes made to lamps, drivers, and dimmers, however, because any change may affect the dimming performance. Products and their technical specifications may evolve between the time of ordering and reaching the job site.

\subsubsection{Specify 3-Wire or NEMA SSL-7A Dimmers for Wall-Box Applications}

For new or major remodel projects, a neutral wire should be brought to all wall-boxes and dimming system panels, allowing for the specification of 3-wire dimmers, which can alleviate many sources of undesirable LED dimming behavior. For existing installations where it is impractical to specify 3-wire dimmers, as is the case for most retrofit applications, the specification of NEMA SSL-7A compliant dimmers should result in predictable LED source performance, if (and only if) SSL-7A compliant sources are also specified.

\subsubsection{Follow Manufacturers' Recommendations}

In instances where mockups are not possible and proven solutions are unavailable, specifiers are strongly advised to obtain and follow dimming guidance from the manufacturers of the LED source(s) and/or dimmer that they want to specify. Guidance should ideally include specific combinations of LED sources and dimmers that exhibit the best possible behavior, and instructions for determining the maximum load that can be connected to that dimmer. Dimmer loading guidance may be available from either manufacturer, and may come in one of two forms:

- A de-rated maximum load rating (in watts) for the dimmer (e.g., 150W instead of 600W). This is provided by the dimmer manufacturer for any/all LED sources

- A minimum and maximum number of LED sources per circuit controlled by the dimmer, applicable for a specific LED source, provided by the dimmer and/or LED source manufacturer

If no maximum dimmer loading guidance is available, the specifier may consider proceeding with the use of a selected line voltage (e.g., INC, but not MLV or ELV) dimmer, de-rated by a factor of 5-10x (e.g., de-rate a $600 \mathrm{~W}$ dimmer down to $120-60 \mathrm{~W}$ ); if a more accurate de-rating is required, contact the 
dimmer (not LED source) manufacturer. If a precise derating value is not available, either consider specifying other products altogether, or use a conservative derating value of 10. See Section 3.2.2.

Specifiers should be wary of manufacturer dimming guidance that is the same for broad categories of dimmers (e.g., all models available from a certain dimmer manufacturer, or all forward-phase dimmers). One approach is to ask what performance claims will be met by following the manufacturer's guidance. For example, if an LED product cut sheet recommends an ELV dimmer, ask for the maximum and minimum number of products that can be controlled by a specific dimmer, the minimum light output achievable, and whether any undesirable behavior (e.g., objectionable flicker, or "ghosting") can occur under any particular circumstances. It is reasonable also to ask whether the manufacturer is willing to back up these performance claims with a written warranty. Trusted manufacturers that offer support and warranties can help reduce uncertainty.

\subsection{Step-by-Step Guidance for New Construction or Major Remodel Projects}

The process for specifying LED dimming is somewhat different for new or major remodel installations than it is for retrofit projects. For a new installation both the dimming system and the LED product can be varied, while in retrofit installations it is necessary to find LED products that will perform as desired with the already-installed dimming system. In either case, the process is potentially difficult and time-consuming. The following is a recommended procedure for specifying LED dimming for new construction or major remodel projects. There are no guarantees that the resulting dimmers and LED products will produce smooth, low-level dimming. However, this procedure raises the chances of success considerably. A step-by-step example for the major remodel of Burden Museum is provided in section 4.2. 
Recommended procedure for specifying LED dimming for new construction or major remodel projects

1. Design the lighting layout and select the control system:

- Select luminaires and/or lamps, and document these in the lighting schedule.

- Select the basic control system (make, model, available load type(s) of dimmers). For wall-box dimmers, select a brand and style that offers a range of load options such as INC, MLV, ELV, or has optional interfaces that allow for the control of MLV, ELV or even 0-10V, as needed.

2. Identify and quantify the LED product(s) used in each dimmer control zone:

- This includes the make and model of LED track head, LED downlight, or LED replacement lamp for a chandelier, for example.

- Count the number of LED luminaires or lamps, total the LED system watts on that dimming zone, and document these in the dimming schedule.

3. Check the current LED product spec sheet (on manufacturer's website) for dimming guidance:

- Look for recommended dimmer model numbers or dimmer types (e.g., INC, ELV), as well as minimum and maximum recommended number of sources per single dimming zone.

- Do this for each integral LED lamp or luminaire. Note this in the luminaire schedule or the dimming schedule.

4. Check the dimmer manufacturer's website for a dimming report for that specific LED source. If there is no dimming guidance from either party, or if there is conflicting guidance, then here are two options:

- Consider selecting a different LED product that is specifically listed for use with that dimmer, or

- Do a mockup to evaluate dimming performance. See mockup guidance in Section 3.1.2.

5. Complete a dimming schedule by zone that includes the LED luminaire type, type of dimmer for zone, maximum power (in watts) used per zone, and minimum/maximum number of lamps allowed per zone.

6. Repeat the steps above for each dimming zone.

\subsection{Step-by-Step Guidance for Existing Projects}

The following is a recommended procedure for specifying LED dimming for an existing project. The lighting industry is in an awkward transition period at this time, in that it is very difficult to identify which LED product will work well in existing dimmer installations without performing a mockup. At the time of this writing, there is no way to guarantee that a specific LED product and specific dimmer make, model and setting will produce satisfactory results, even if LED product manufacturer literature suggests compatibility. However, there are ways to reduce uncertainty. A step-by-step example following this guidance for an existing church project is provided in section 6.0. 
1. Identify the existing dimming system, its maximum load capacity, and its load type(s):

- Visually inspect the system, or refer to architectural drawings and submittals for the project.

- If possible, obtain the relevant technical documentation from the dimming system manufacturer. Identify the maximum load capacity (in watts) of the specific dimmer for the first zone of lighting (e.g., 1920W) where LED replacement lamps or luminaires are being considered and identify the load type that it is set to control (e.g., INC, MLV, ELV).

2. Identify the installed luminaire for that zone, and its existing lamping (e.g., $90 \mathrm{~W}$ halogen PAR38 $40^{\circ}$ flood, or 50W $12 \mathrm{~V}$ halogen MR16 $10^{\circ}$ spot).

- If the luminaire contains a transformer, note whether it is a magnetic or electronic transformer, and note the brand name and model number of the transformer, if possible.

3. Identify the LED product(s) selected to replace the existing lamp, its wattage, and specifications.

- This is usually an LED integral lamp replacement for an existing track head or downlight or chandelier. It is important to know the specifications of this LED replacement lamp.

4. Count the number of LED lamps or luminaires (and total watts) on that dimming zone.

5. Check the LED product manufacturer's website for a recommended dimmer type (e.g., INC, MLV, ELV), any behavior description ("dims down to only 20\%", for example), and the maximum and minimum number of lamps that are recommended for use with the dimmer.

6. Check the dimmer manufacturer's website for a report on the specific dimmer's behavior with the specific LED product. If there is no dimming report available, or if there is conflicting information, then here are two options:

- Consider selecting a different LED product that is specifically listed for use with that dimmer, or

- Do a mockup to check for compatibility and dimming performance. See mockup guidance in Section 3.1.2.

7. Repeat this process for each dimming zone. 


\subsection{Potential Post-Specification Issues}

\subsection{Mixing Multiple Light Sources}

In a building with lighting track, where one LED track product is used on light track in one area and a different LED track product is used elsewhere, the specifier should consider whether the users will mix or swap track heads. If it's a possibility, the dimming system may not be able to control both forward-phase and reverse-phase LED products at the same time on the same zone. There's a small possibility this mix could result in failure of the LED, driver, or dimmer at some point in the future. At the very least, the two types of products certainly wouldn't dim similarly. It is important to either change the design in advance to prevent this from happening, or else discuss with the client how to minimize this possibility.

If the client mixes light sources on a single control zone, compatibility issues may arise. A combination of different brands of LED PAR38 lamps, halogen lamps, low-voltage halogen luminaires, and/or dedicated LED luminaires may produce dramatically different dimming rates and minimum levels. Sometimes adding a simple halogen lamp to a circuit may even improve dimming behavior. At this point, there is no way to anticipate these dimming behaviors without a full-scale mockup.

\subsection{The Effect of Time, Change, and Substitutions}

In architectural construction projects, changes happen. Projects may be delayed for a myriad of reasons. When the projects are resumed, the original products specified may have undergone LED or driver generation changes or dimmer model design evolution, or both, and products may have been discontinued or modified. All of these can affect the careful compatibility work done early in the project, and therefore all LED products should be checked for compatibility with dimming systems once again right before the lighting and controls are purchased. If there are any substitutions of dimmers, luminaires, lamps, or transformers on the project, compatibility needs to be reevaluated (and in some cases tested through mockups) and documented. Parties proposing product substitutions should be aware that additional design team time and cost may be incurred for this evaluation process. 


\subsection{New Construction or Major Remodel Project Example: Burden Museum}

The Burden Iron Works Museum, located in Troy, N.Y., is an 1882 building jewel undergoing restoration and preservation (Figure 5). Mesick Cohen Wilson Baker is the architecture firm that has done the restoration design work; Quantum Engineering has provided the electrical design.

\subsection{Project Background}

Jan Moyer Design is designing lighting and controls that will celebrate the museum's collection of horseshoes, collars, knitting machines, rototillers, bells, and other pieces from the area's industrial past. The lighting will be incorporated into an interactive exhibit on the museum floor that will allow visitors to use a touchscreen to follow the evolution of lighting from gaslight to the present (Figure 6). The first touchscreen selection will cause the museum lighting to look like it was at its opening in December 1882, just three months after Thomas Edison opened his Pearl Street Station in southern Manhattan, the first operational commercial incandescent lighting system in the world. LEDs will simulate the gaslights in reproduction chandeliers. A second selection will invoke the lighting chronologically from early lowwattage incandescent lighting all the way up to dimmable LEDs. Along the way, the touchscreen will provide information about each era's lighting technology, its effectiveness and efficiency, and its appearance.

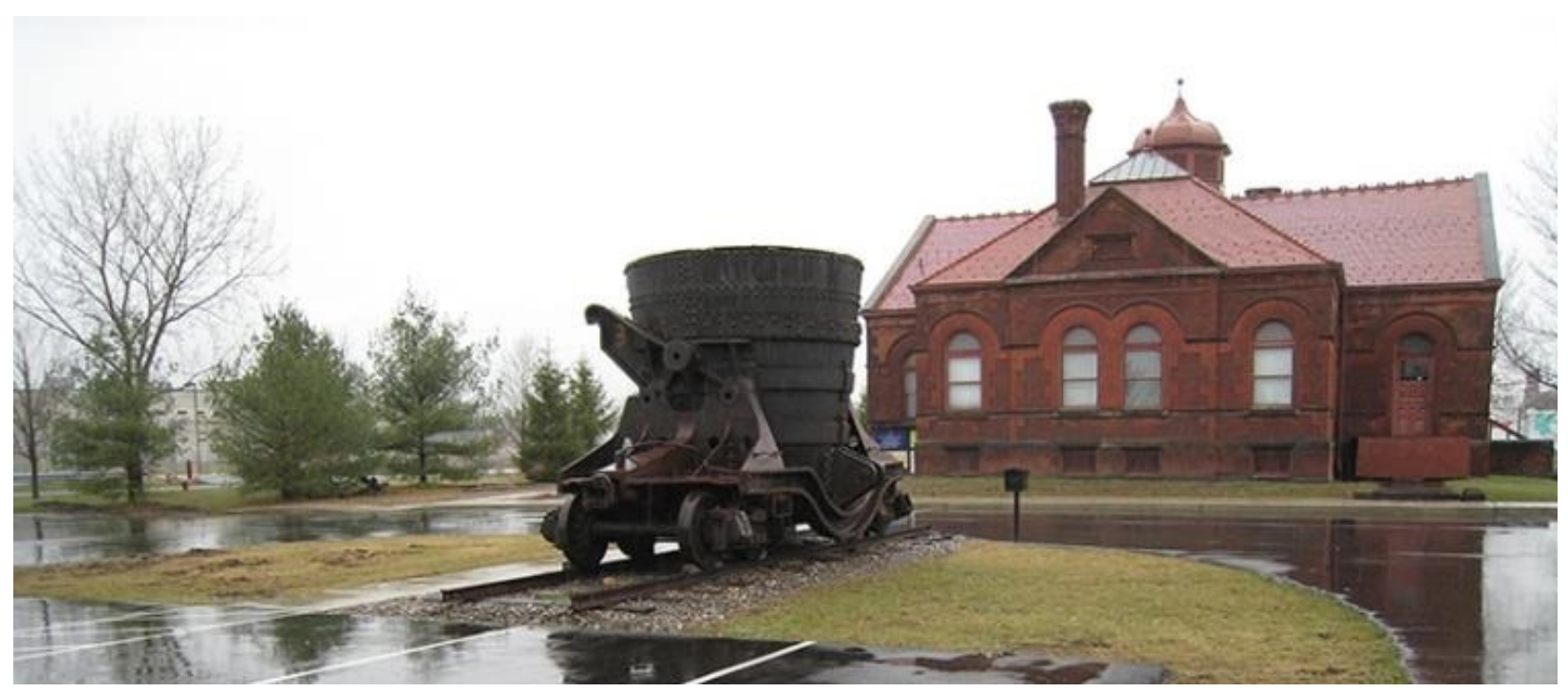

Figure 5. The Burden Museum, Troy, NY. (Photo courtesy The Hudson Mohawk Industrial Gateway.)

The Museum has received grants from Brookfield Renewable Power, Inc. and from the New York State Energy Research and Development Authority (NYSERDA) to demonstrate energy-efficient solidstate lighting, specifically focusing on the integration of LEDs and controls. DOE's GATEWAY program has assisted in the selection of compatible LED and dimming products for the project, and the documentation of a design process that is not yet straightforward. 


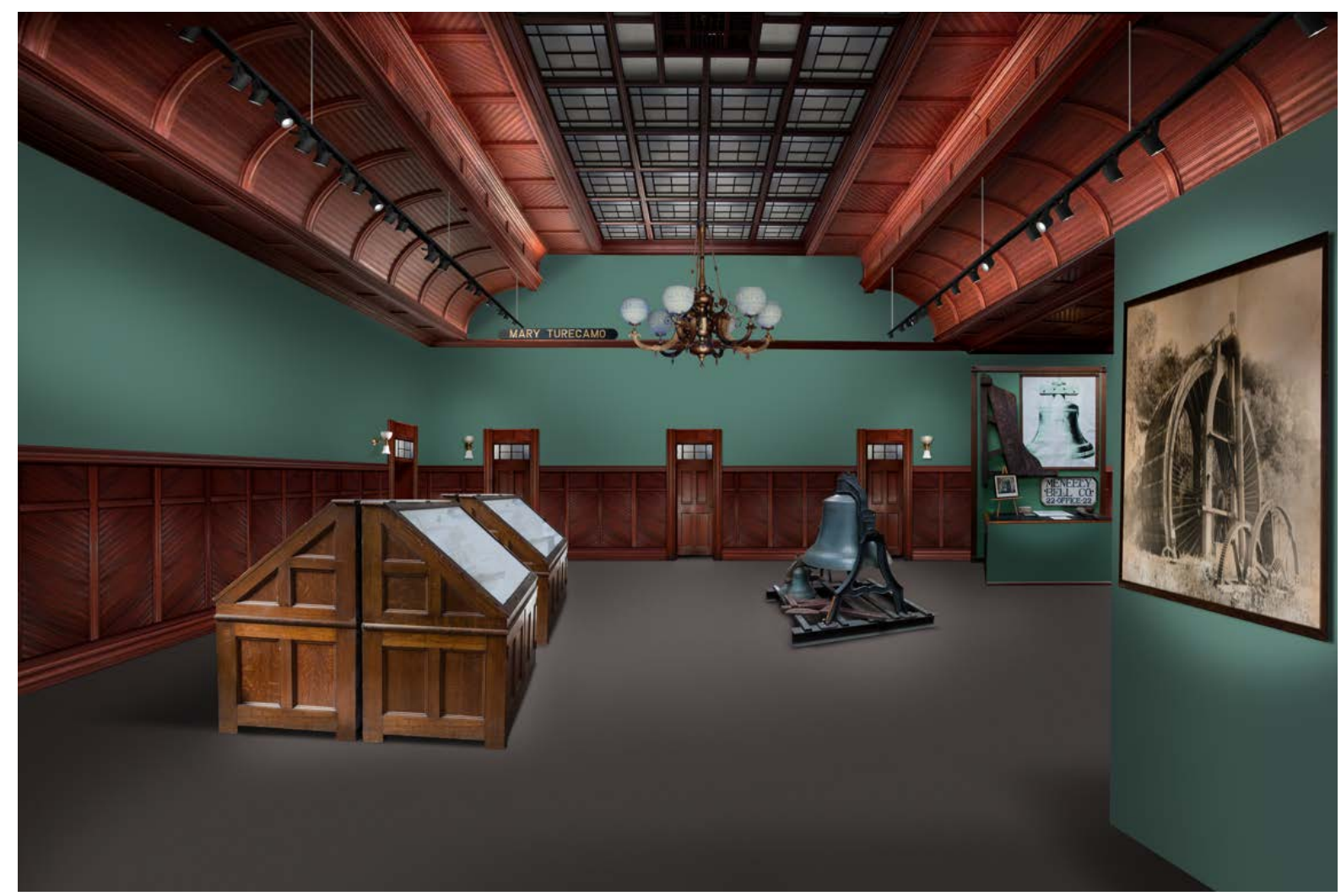

Figure 6. Computer-rendered visualization of the completed interior. (Photo courtesy George Gruel, Oddstick Studio.)

\subsection{Example Controls Design and Specification Process}

Until the performance of LED sources with various dimming systems becomes more predictable, the process that follows is one that specifiers can use to minimize complications and maximize chances for dimming that meets the client's expectations. The following sections outline how the step-by-step process introduced in Section 3 was applied in the Burden Museum major renovation, and references the LED products and controls specified. Lighting plans and layouts, fixture schedules, and product data sheets are all provided in the Appendices; the reader may find it easier to follow these steps by printing out the documents, making them more readily referenced while following the text.

The specific LED and dimming products described in this example were specified in 2012. Many of them are no longer available because of LED chip generation changes, electronic design changes in drivers and dimmers, or other reasons. However, the principles and procedures remain current. 


\subsubsection{The Main Hall and Entry Area}

\section{Design the lighting layout and select the control system:}

- Select luminaires and/or lamps, and document these in the lighting schedule.

- Select the basic control system (make, model, available load type(s) of dimmers). For wall-box dimmers, select a brand and style that offers a range of load options such as INC, MLV, ELV, or has optional interfaces that allow for the control of MLV, ELV or even 0-10V, as needed.

This step was completed at the Burden Museum by establishing the lighting plan, with realistic counts and specifications of lamps per chandelier, lamps per track run, and LED wattage per linear foot of cove light. Luminaire manufacturer product numbers and LED drivers were all selected, and when luminaires were identified as "low-voltage," the luminaire schedule identified whether the transformer feeding the track was AC or DC, magnetic or electronic, and its rated capacity. See the Burden Museum Lighting Plans and Luminaire Schedule in Appendices A-D. The Lutron Grafik Eye QS Series preset control system was selected for this Burden Museum project (Appendix E, Figure E.1 and Figure E.2). This system has a number of load types and sizes per zone that can be set in the field (such as INC, MLV, neon, fluorescent, non-dim). Other load types can be controlled by installing an interface ("black box") between the dimmer and the load that will allow dimming of larger or more complex load types (ELV, 0 10V, DALI, etc.) Where wall-box dimmers are used, a Lutron Radio Ra product was selected, which offers a range of options such as INC, MLV, ELV, or has optional interfaces (for wiring between the dimmer and the load) that will permit $0-10 \mathrm{~V}$, if needed.

\section{Identify and quantify the LED product(s) used in each dimmer control zone:}

- This includes the make and model of LED track head, LED downlight, or LED replacement lamp for chandelier, for example.

- Count the number of LED luminaires or lamps, total the LED system watts on that dimming zone, and document these in the dimming schedule.

This Burden Museum project has three preset scene controllers (PSC). (See the sample dimming schedule in Appendix E, Figure E.3.) Beginning with the LED luminaires controlled with PSC-1: The first two zones on the dimming schedule for PSC-1 in Appendix E were examined. Control zones 1 and 2 are dimming the two-circuit track lighting located in the Entry Hall, which uses PAR38 track heads. There are three runs of track with nine T4 track heads total per circuit of track. The lamping is the Philips Enduraled 16W PAR38 lamp according to the luminaire schedule. (See Appendix E, Figure E.4 for the track plan, Figure E.5 for the track head and lamping information, and Figure E.6 for the Philips LED PAR38 lamp dimming guidance.)

\section{Check the current LED product spec sheet (on manufacturer's website) for dimming guidance:}

- Look for recommended dimmer model numbers or dimmer types (e.g., INC, ELV), as well as minimum and maximum recommended number of sources per single dimming zone.

- Do this for each integral LED lamp or luminaire. Note this in the luminaire schedule or the dimming schedule. 
Looking at the Philips PAR38 lamp’s compatible dimmer list, there are wall-box dimmers listed, but no architectural dimming systems.

\section{Check the dimmer manufacturer's website for a dimming report for that specific LED source. If} there is no dimming guidance from either party, or if there is conflicting guidance, then here are two options:

- Consider selecting a different LED product that is specifically listed for use with that dimmer, or

- Do a mockup to evaluate dimming performance. See mockup guidance in Section 3.1.2.

Turning instead to the Lutron dimmer compatibility report card for this specific Philips lamp (Appendix E, Figure E.7) reveals that it is compatible with the Lutron QSG-6D controller. The controller can dim between 1 and 14 lamps per dimming zone with a "smooth and continuous" performance, and the minimum dimming level is $2 \%$. No special interface is needed as long as no more than 14 of these LED lamps are powered in a single dimming zone. Because no special dimmer type is specified in the dimming report, it is reasonable to assume the default dimmer type, forward phase-cut incandescent, is the compatible dimmer setting on the QSG-6D. Following step 5, the specifier notes this in Zones 1 and 2 of the dimming schedule (Appendix E, Figure E.3) as step 5, excerpted in Figure 7.

5. Complete a dimming schedule by zone that includes the LED luminaire type, type of dimmer for zone, maximum power (in watts) used per zone, and minimum/maximum number of lamps allowed per zone.

\begin{tabular}{|c|c|c|c|c|c|c|c|}
\hline PSC-1 & & Museum & ain Hall an & Entry Hall, Trac & ighting & & \\
\hline $\begin{array}{c}\text { Control } \\
\text { Zone }\end{array}$ & Zone Liahti & Fixture & Fixture & Fixure Load & $\begin{array}{l}\text { Maximum } \\
\text { Watts per }\end{array}$ & $\begin{array}{l}\text { Total } \\
\text { Zone }\end{array}$ & Remarks \\
\hline niwoer & & Type & Quantity & Type & Track Head & wownce & \\
\hline 1 & Track accent 1 - Entry Hall & $\mathrm{T} 4$ & 9 & \multirow{3}{*}{$\begin{array}{l}\text { LED integral } \\
\text { lamps for }\end{array}$} & 16 & 144 & \multirow{6}{*}{$\begin{array}{l}\text { Pimming mfg } \\
\text { recommends } 1 \\
\text { to } 14 \text { lamps per } \\
\text { dimmer, smooth } \\
\text { dimming down } \\
\text { to } 2 \%\end{array}$} \\
\hline 2 & Track accent 2 - Entry Hall & T4 & 9 & & 16 & 111 & \\
\hline 3 & Track accent1 woot & T1 & 9 & & 16 & 144 & \\
\hline 4 & Track accent 2 - West & $\overline{T 4}$ & 11 & \multirow{3}{*}{$\begin{array}{l}\text { Forward Phase } \\
\text { Incandescent } \\
\text { Dimmer }\end{array}$} & 16 & 176 & \\
\hline 5 & Track accent 1 - East & T4 & 11 & & 16 & 176 & \\
\hline 6 & Track accent 2 - East & T4 & 9 & & 16 & 144 & \\
\hline & & & & \multicolumn{2}{|c|}{ TOTAL LOAD (WATTS) } & 928 & \\
\hline
\end{tabular}

Figure 7. Section of dimming schedule for Main Hall and Entry Hall, showing track lighting zones.

\section{Repeat the steps above for each dimming zone.}

The third, fourth, fifth, and sixth channels of the Lutron QSG controller labeled PSC-1 are dimming four circuits of track lighting T4 in the Main Hall, with the same LED PAR38 lamps, so the same steps are used to complete the dimming schedule in Appendix E, Figure E.3. None of the dimming zones uses more than 14 lamps, so the dimming should be smooth and continuous, and no additional interface is needed for any of these dimming zones.

To check compatibility for the next group of luminaires, proceed to the dimming schedule for PSC-2 in Appendix E, Figure E.3. PSC-2 controls the Main Hall and Entry Hall chandeliers, as well as the cove 
lighting in the Main Hall (Appendix E, Figure E.11). The same steps are followed, although they have been combined in the narrative:

\section{Design the lighting layout and select the control system.}

2. Identify and quantify the LED product(s) used in each dimmer control zone.

3. Check the current LED product spec sheet (on manufacturer's website) for dimming guidance.

4. Check the dimmer manufacturer's website for a dimming report for that specific LED source.

5. Complete a dimming schedule by zone.

6. Repeat the steps for each dimming zone.

PSC-2's first zone dims the globes of the large chandelier, CH1 (see Appendix E, Figure E.8). The load consists of 12 of the Philips Enduraled 12W A-LED lamps. A dimming report card on the Lutron website (Appendix E, Figure E.9) indicates this lamp can be operated on a forward-phase dimmer of the Lutron QSG controller, but the maximum number of lamps per zone is 9. However, all the lamps can be operated on a single zone by adding a phase-adaptive power module (PHPM-PA) interface to the zone, which will convert the forward-phase voltage modulation of the zone's dimmer into a larger capacity dimmer that can accommodate the increased momentary load the LED products' draw from the dimmer due to repetitive peak currents. This effectively increases the maximum number of lamps allowed on this zone to 21. (The PHPM-PA interface is a "black box" wired between the dimmer output and the load, located in an accessible but out-of-sight location. See Appendix E, Figure E.10.)

The second zone on the PSC-2 dimmer switches the ring of amber LEDs in each chandelier globe (illustrated in Appendix E, Figure E.8), which is on-off only control, so the standard non-dim setting of the Lutron QS System will handle the load. There are 12 LED rings in the second PSC-2 control zone.

The third zone on the PSC-2 dimming schedule dims the LED A-lamps of two 6-globe chandeliers, 12 in all. The 12 lamps exceed the 9-lamp maximum listed in the report card; therefore, like the dimmer for the 12-globe chandelier, the PHPM-PA interface will need to be installed between the dimmer and the load to increase the dimmer zone capacity.

Zone 4 of the PSC-2 is identical to zone 2, addressed above.

Zones 5 and 6 dim the linear LED striplights (luminaire type L2) mounted in two levels of uplight coves. (See Appendix E, Figure E.11 for the cove lighting plan, Figure E.12 for the catalog cut, and its power supply in Figure E.13.) The MODA LIGHT "SuperFlex" product uses a 24V DC magnetic transformer plus control circuitry on the secondary side of the transformer. (See cove lighting plan in Appendix E, Figure E.11) According to MODA LIGHT's website, the product is dimmable using a TRIAC (forward phase-cut) dimmer. That is the standard setting for the Grafik Eye QSG dimmer zone, and there is no special limit on the number of LED products used as long as the transformer for the LED load doesn't exceed the 600W capacity of the dimming zone. (This is one advantage of dimming the magnetic transformer/inverter. Its maximum load is calculated solely in watts of transformer capacity.)

That completes the work of designing the control system for the Main Hall and Entry Hall, checking for compatibility with the LED lamps and luminaires. The dimming schedule for the PSC-2, showing the control zones for the chandeliers and cover lighting of the Main Hall and Entry Hall, can now be completed, as shown in Appendix E, Figure E.3. 
There are other areas in the building where there is dimming to be coordinated with LED products, but the products are very similar to those discussed for PSC-1 and PSC-2. Instead, the next section describes steps followed to check for compatibility in an area that uses dedicated LED track heads.

\subsubsection{Storage/Collection Area, with Wall-Box Controller and Conflicting Information}

The original bank vault in the Burden Museum is used for storage and archiving of historical documents, and may become a display space in the future. Called the Storage space/Vault, it is lighted with dedicated LED track heads rather than LED lamps that screw into incandescent sockets.

The room can be found near the top of the plan in Appendix B. Appendix F, Figure F.1, shows an enlarged plan. On the plan, a wall-box dimmer is shown to dim the type T8, Amerlux Contour Vertical 3x3 LED track heads. Amerlux's catalog sheet says the track head can be dimmed with an electronic lowvoltage (i.e., reverse phase-cut) ELV dimmer (Appendix F, Figure F.2). No restriction on the maximum number of track heads is listed.

However, the Lutron report card for the same product shows it to be compatible with a three-wire or Eco-system (fluorescent) wall-box dimmer, rather than an ELV dimmer, with a maximum number of 59 of these LED track heads per dimmer (Appendix F, Figure F.3).

The difference may arise from Amerlux's offering the track head with two separate drivers, one with a Lutron dimming driver and the other with a driver compatible with the ELV dimmer. This is not explicitly stated on the catalog spec sheet, but either way, the specifier needs guidance in how to specify the product appropriately.

In this case, the track head was not specified by the lighting designer with the Lutron driver, so an “adaptive dimmer” from Lutron's Radio Ra2 line was selected, because that dimmer can automatically adapt to the load and provide an ELV dimming waveform to the track system (Appendix F, Figure F.4) This dimmer requires a neutral wire in the electrical wall box.

A future concern is there are two kinds of Amerlux track heads used on this project, located in two different spaces. They are interchangeable on the track system, and there is a chance that future exhibit curators and designers will mix the two types of heads (LED track head and retrofit LED lamp track head) on the same track. If so, the Grafik Eye QSG dimmer could not control both forward-phase and reversephase LED products at the same time on the same zone, and this could result in failure of the LED, driver, or dimmer. At the very least, the two types of products certainly wouldn't dim similarly. It is important to discuss this with the client, or to choose track heads that use the same dimming method. 



\subsection{Existing Project Example: Hudson River Valley Church}

\subsection{Background}

Four years ago, a church in the Hudson River valley of New York underwent an architectural remodel to accommodate new worship approaches, improve its liturgical relevance, and enhance its overall appearance and functionality. The design included an architectural control system by Crestron, which gave the worship leaders and musicians great flexibility in light levels and effects. The principal lamps used at that time were halogen MR16s and PAR38s, because these offered the greatest range in smooth dimming and supported the liturgical needs of the worship space (Figure 8 and Figure 9). An abbreviated luminaire schedule is shown in Appendix G, Figure G.1. Note that the MR16 track heads contain an integral electronic transformer.

In 2013, the church was interested in reducing maintenance frequency on the halogen lamps, reducing heat from the lamps, and reducing the utility bills. It was important to keep the lamp color as warm as possible because of the finishes and artwork in the worship space. LED replacement lamps were suggested, but the facility manager was concerned that the church might not get the same smooth dimming when the LEDs were combined with the existing control system. What follows is the evaluation process for the LED lamp recommendations to the congregation.

(Although this is not a GATEWAY demonstration, it is an example of a real-life project dealing with the process of evaluating LED replacement lamps and their performance on an existing phase-control architectural dimming system. The example is used courtesy of the architect and the church.) 


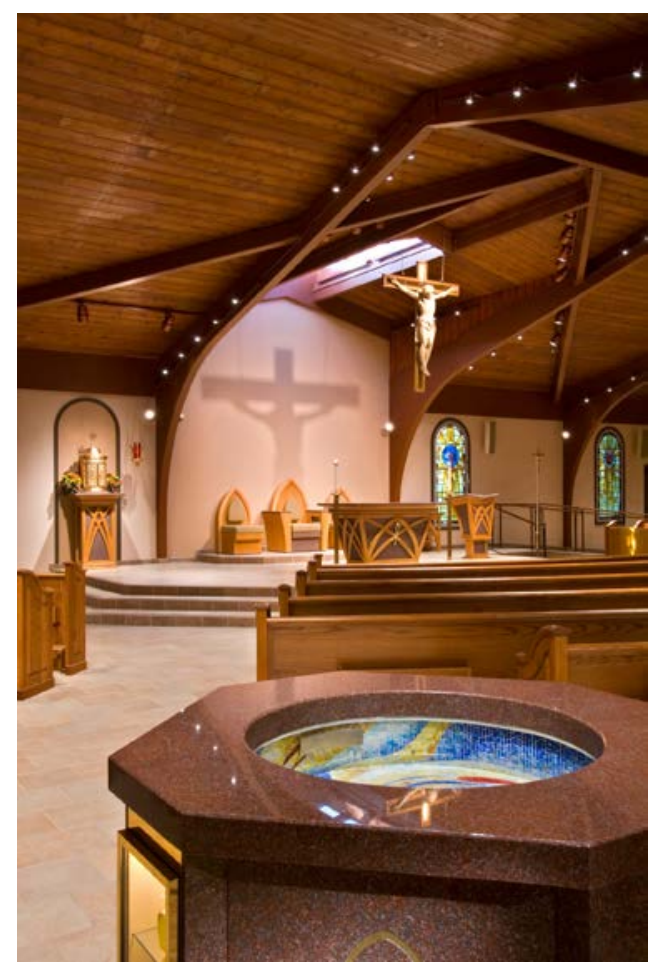

Figure 8. View of altar and platform area, lighted with PAR38 track heads. (Foresight Architects, Schenectady N.Y.; Randall Perry Photography, Schaghticoke, N.Y.)

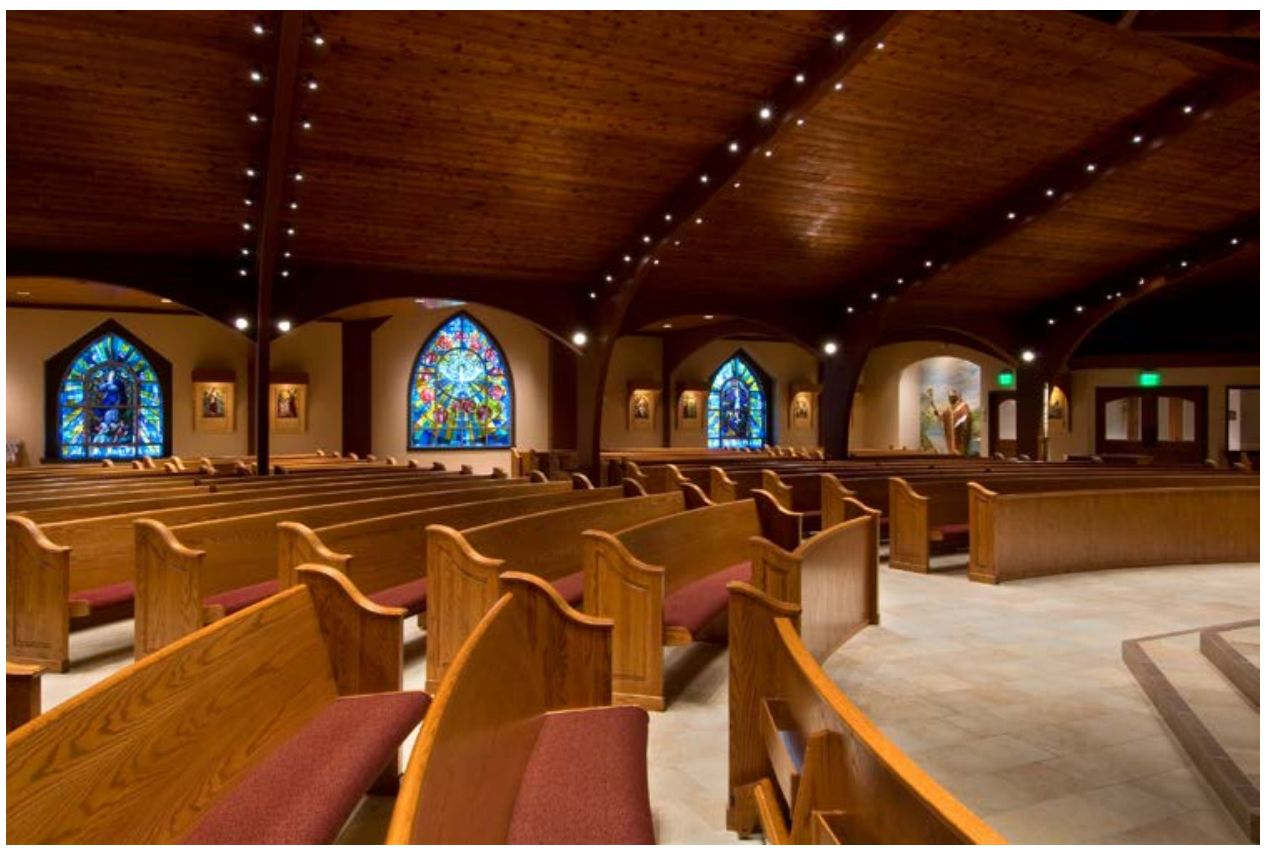

Figure 9. View of Hudson River valley worship space, showing track mounted to beams with MR16 track heads aimed downward into pews. (Foresight Architects, Schenectady N.Y.; Randall Perry Photography, Schaghticoke N.Y.) 


\subsection{Suggested Approach to Resolving the Issue of Smooth Dimming at the Church}

For the low-voltage MR16 track heads aimed down into the pews (fixture type T1) for reading light, there are no perfect LED options. The least expensive and most reliable solution is to replace the existing 50W MR16 lamps with halogen infrared (HIR) 37W MR16 lamps. These lamps are fully dimmable and should produce nearly the same amount of light and beam size for one-third lower wattage. They would dim smoothly down to $1 \%$ levels or less. No adjustments to the dimming system would be needed.

However, were the congregation willing to accept about 20\% less light in exchange for dramatic power savings and much longer lamp life, a 7W 3000K LED MR16 was proposed as an effective solution.

The following steps are based on the assumption that the congregation is motivated to pursue the LED option.

\subsection{Example Controls Design and Specification Process}

Following the steps outlined in section 3.3 for existing projects:

\section{Identify the existing dimming system, its maximum load capacity, and its load type(s).}

The dimming system at the church is a Crestron GLE dimmer panel with Pac2m control panel, 24 channels with 12 preset scenes. Each channel is rated for 1920W and can be set to INC, MLV, or ELV. The current dimmer settings for the MR16 halogen luminaires is INC, a forward phase-cut setting.

\section{Identify the installed luminaire for that zone, and its existing lamping.}

The T1 track head used in the first dimming zone is a Lighting Services, Inc. 216-00, specified with a 50W halogen MR16 lamp and integral 12V electronic transformer (Appendix G, Figure G.2). The make and model of electronic transformer is unknown.

3. Identify the LED product(s) selected to replace the existing lamp, its wattage, and specifications.

The proposed LED lamp is the LED7XDMR16D83035 by GE. Its cut sheet is shown in Appendix G, Figure G.3.

4. Count the number of LED lamps or luminaires (and total watts) on that dimming zone.

Consulting the original lighting plan, the number of track heads per dimmer varies, but does not exceed 16. 
5. Check the LED product manufacturer's website for a recommended dimmer type (e.g., INC, MLV, ELV), any behavior description ("dims down to only 20\%," for example), and the maximum and minimum number of lamps that are recommended for use with the dimmer.

The compatible dimmer information is seen in Appendix G, Figure G.4. Because the exact brand of electronic transformer inside the track heads is unknown, there's no way to know for certain whether this product would dim better on a forward-phase dimmer (MLV) or a reverse-phase dimmer (ELV). However, GE's dimming compatibility tables suggest ELV is likely to work best with an electronic transformer.

\section{Check the dimmer manufacturer's website for a report on the specific dimmer's behavior with} the specific LED product. If there is no dimming report available, or if there is conflicting information, then here are two options:

- Consider selecting a different LED product that is specifically listed for use with that dimmer, or

- Do a mockup to check for compatibility and dimming performance. See mockup guidance in Section 4.0.

There was no dimming information for this specific lamp on the Crestron website. The dimming guidance from the GE LED lamp literature (Appendix G, Figure G.4) suggested that reverse-phase dimming was likely to produce the best results, so the congregation was advised to try the GE LED lamp in a mockup, changing the dimmer setting to reverse phase. It is wise to try this with only one dimming zone of lamps, in order to reduce the expense of buying all lamps needed, and to avoid having to return them to the vendor should the dimming not meet the needs.

\section{Repeat this process for each dimming zone.}

To test another LED replacement lamp type for the Hudson River Valley Church, the process is repeated for PAR38 halogen lamps. 60W HIR lamps are currently used in track lighting (luminaire type T5), and 100W lamps used in recessed downlighting (luminaire type D1 in Appendix G, Figure G.1). Since the proposed lamps are from the same manufacturer's family, and are being operated on the same type of dimmer, they are treated together here in each step for checking dimming compatibility:

\section{Identify the existing dimming system, its maximum load capacity, and its load type(s).}

The dimming system is a Crestron GLPD dimmer panel with CLX-2DIM8 dimmer modules, and user control interface providing 24 dimming zones with 12 preset scenes. Each zone is rated for $1920 \mathrm{~W}$ and can be set to INC, MLV, or ELV (and more) loads. The current dimmer settings for the PAR38 halogen luminaires is INC, a forward phase-cut setting. The maximum capacity for each dimmer is $1920 \mathrm{~W}$.

\section{Identify the installed luminaire for that zone, and its existing lamping.}


The D1 recessed downlights used in this dimming zone are Kurt Versen PAR38 luminaires, specified with 100W HIR PAR38 $40^{\circ}$ flood lamps. The T5 track lights are made by Lighting Services, Inc. and use 60W HIR PAR38 $40^{\circ}$ flood lamps.

\section{Identify the LED product(s) selected to replace the halogen lamp, its wattage, and specifications.}

The proposed LED lamps are the Acuity Brands “Acculamp ALSP38-2000L-45-DIM 25W LED” for the D1 downlights with 100W PAR38 lamps; and the Acuity Brands "Acculamp ALSP38-1200L-45-DIM 20W LED” for the T5 track lights with 60W halogen lamps. Their cut sheet is shown in Appendix G, Figure G.5.

\section{Count the number of LED lamps or luminaires (and total watts) on that dimming zone.}

Checking the original lighting plans, the number of D1 recessed downlights on the control zone is 16 . The number of $\mathrm{T} 5$ track heads also does not exceed 16.

\section{Check the LED product manufacturer's spec sheet for a recommended dimmer type (e.g., INC,} MLV, ELV), any behavior description ("dims down to only $20 \%$ ", for example), and the maximum and minimum number of lamps that are recommended for use with the dimmer.

Acculamp suggests that it is likely to dim down to $10 \%$ and lists a web link to its online guide to dimmer compatibility for this lamp. It suggests a reverse phase-cut (ELV) dimmer will work best with the Crestron architectural dimming system, and also indicates a low-end adjustment may be needed to prevent unstable behavior below its minimum output. See Appendix G, Figure G.6.

Crestron's dimming compatibility page (Appendix G, Figure G.7) also recommends the reverse phase dimming setting for the 1200 lumen product, to reduce possible flicker or buzzing at the low end of output. Although it did not specifically test the 2000 lumen product, it is reasonable to assume a similar driver design in each lamp, and thus similar dimming guidelines.

\section{Check the dimmer manufacturer for a report on the specific dimmer's behavior with the specific}

LED product. If there is no dimming report available, or if there is conflicting information, then here are two options:

- Consider selecting a different LED product that is specifically listed for use with that dimmer, or

- Do a mockup to check for compatibility and dimming performance. See mockup guidance in Section 3.1.2.

The Crestron guidance in Appendix G, Figure G.7 does not list minimum and maximum numbers of lamps for the dimmer, so a full-scale mockup is strongly recommended.

The guidance in step 6 led to the following mockup recommendation for the D1 downlight control zone and the T5 track light control zone: 
- Manually switch the zone's dimmer from forward phase-cut (INC or MLV) to reverse phase-cut (ELV) mode.

- Install the PAR38 LED lamps in every socket controlled by this dimming zone. Test whether the lamps dim smoothly, from top to bottom, without noise or flicker. Check to see whether the lamps become unacceptably unstable at or below $10 \%$ of light output.

- If unacceptable behavior is observed, try manually changing the type of dimming for that zone back to forward phase-cut dimming. Test the dimming behavior again, in case it proves to be better. In either case, it may be necessary to set the low end trim so that the lamps extinguish before they reach the point of instability. If this output level is not low enough for the congregation's needs, a different brand of lamp needs to be investigated.

Every dimming zone on the church's control system needs to be analyzed for the proposed LED lamps. Although there is no guarantee of absolute success, this approach can save a great deal of cost and frustration in trying to help clients embrace energy efficient LED products in existing dimming applications. 


\subsection{Conclusions}

LEDs themselves are inherently dimmable, but not necessarily with every driver, and not with every dimmer. This report addresses issues with phase-cut dimmers, which are the most common type currently found in the architectural world. The interactions between the electronic designs of drivers and phase-cut dimmers can produce undesirable dimming performance.

The designer/engineer/specifier that sets out to develop a dimmable LED system should be fully aware of the effort that is presently required to ensure satisfactory dimming performance. One viable option that should be considered is to avoid the need for dimming LED products if possible. If lower light levels can be alternatively achieved through a wise design using multiple lighting switch groups, the results will be predictable and easier to design and implement. Where dimming is needed for mood, specific activities, daylight compensation, energy savings, or other reasons, the specifier needs to understand: that the performance of the LED product is a function of its driver rather than the LED package; that the dimming performance is dependent both on the specific design of the LED source and the specific dimmer; why dimming with traditional phase-cut dimmers is complex; and the detail-oriented process that will be required for producing dimming that meets client expectations.

Excellent-quality LED dimming with phase-control dimmers can be achieved, but it requires fullscale dimming mockups or diligent research by the specifier into compatibility for every combination of dimmer and LED product. For wall-box dimming in smaller-scale applications, specifying 3-wire dimmers can reduce some erratic dimming behavior; and for 2-wire dimming applications, NEMA SSL7A compliant dimmers and LED sources can raise chances for success because it guarantees some level of performance from pairings of compliant products. In the absence of good dimming guidance, this report provides a conservative means to derate phase-control dimmers, thereby protecting them from overloading by LED sources, but not implying a level of dimming quality.

Some current LED products are already showing dramatically improved dimming on existing phasecut dimmers relative to their predecessors. With time, LEDs sources, their components, and dimming systems will evolve and improve; until then it is hoped this report will be a useful reference.

Excellent dimming almost indistinguishable from incandescent behavior is also available from approaches other than phase-control. Specifiers should consider alternatives such as DALI, 0-10V, DMX, or even wireless dimming approaches. These also have their positive and negative attributes, and varying (typically higher) costs, but may result in higher levels of performance, more predictability, and fewer headaches. 



\section{Appendix A: Burden Museum Main Room Lighting Plan}

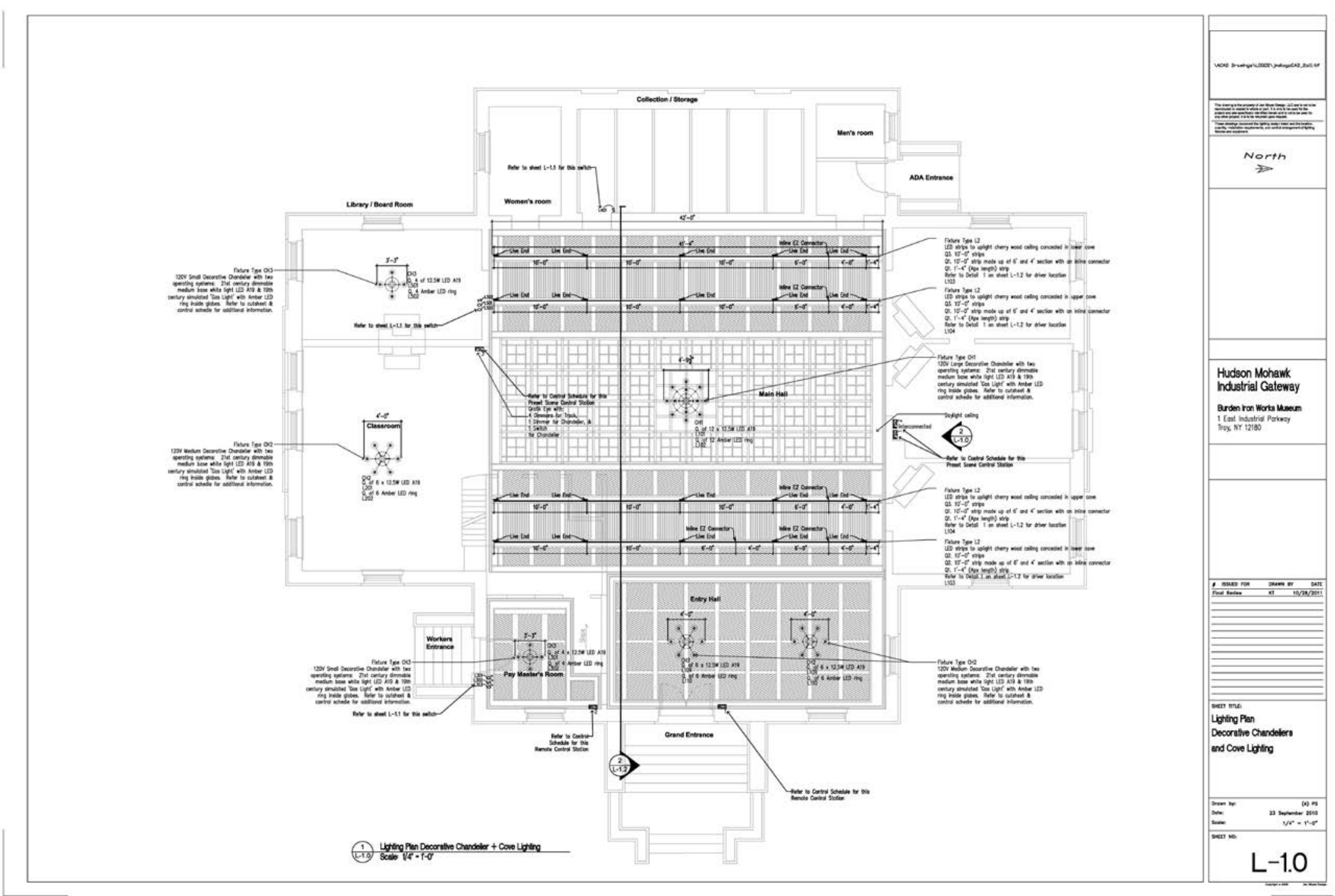



Appendix B: Burden Museum Main Room Track Lighting Plan

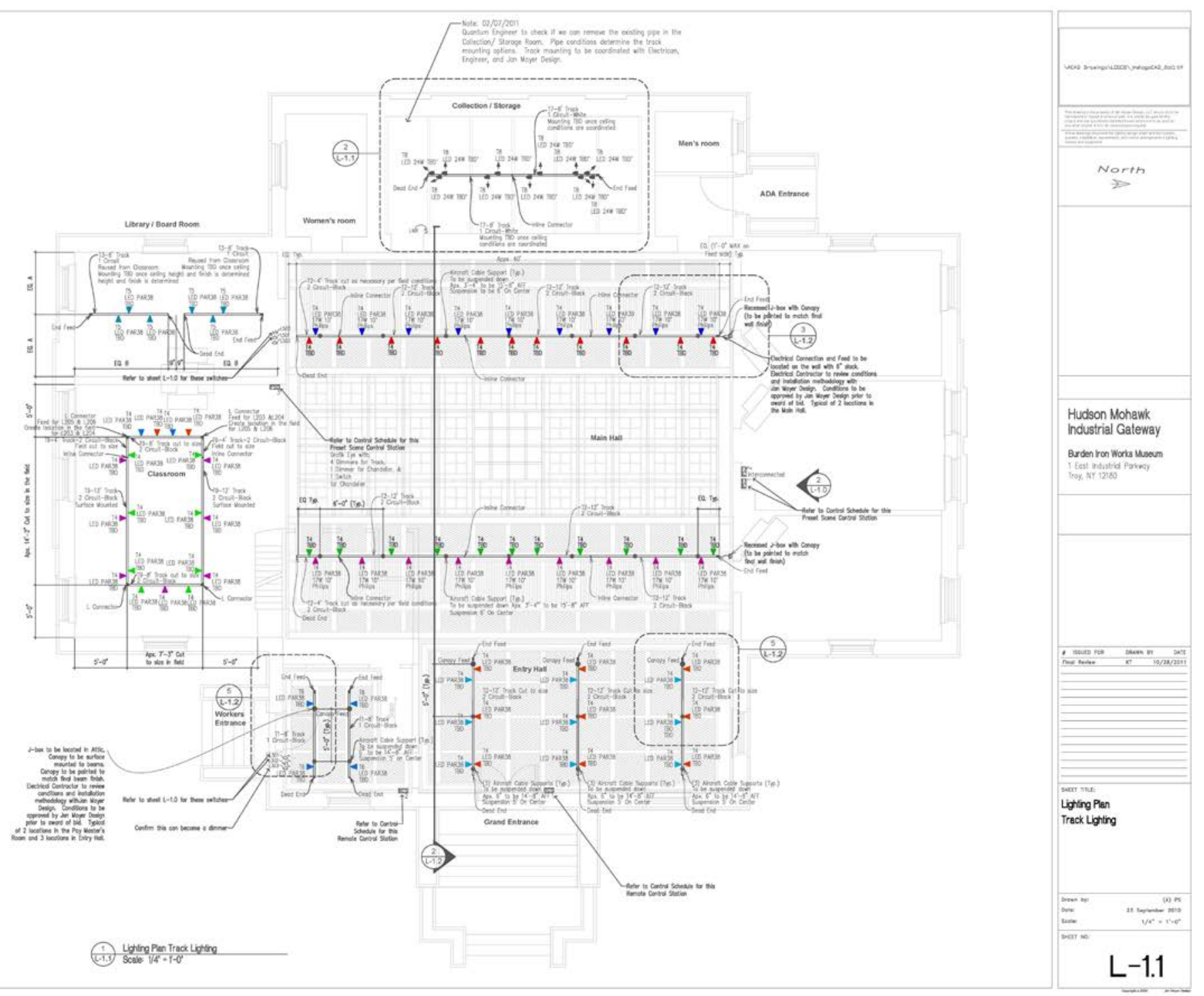





\section{Appendix C: Burden Museum Interior Luminaire Schedule for the Main Hall and Entry Hall}

\begin{tabular}{|c|c|c|c|c|c|}
\hline \multicolumn{6}{|c|}{ INTERIOR LIGHTING FIXTURE SCHEDULE } \\
\hline \multicolumn{6}{|c|}{ MUSEUM MAIN HALL \& ENTRY HALL } \\
\hline Type & Description & Volt & Lamp & $\begin{array}{c}\text { Max } \\
\text { Watts }\end{array}$ & Manufacturer \\
\hline L2 & $\begin{array}{l}\text { LED Strip for mounting in } \\
\text { ceiling coves as uplight, with } \\
\text { dimmable driver. } 3000 \mathrm{~K} \\
\text { warm-white color, } 115^{\circ} \text { beam } \\
\text { angle. Run lengths } 41^{\prime}-4^{\prime \prime} \text {. }\end{array}$ & $\begin{array}{l}120 \mathrm{~V} \mathrm{AC} \text { in/ } \\
12 \mathrm{~V} \mathrm{DC} \text { out }\end{array}$ & $\begin{array}{c}0.16 \mathrm{~W} \text { per } 3000^{\circ} \mathrm{K} \text { LED, } 37 \\
\text { LEDs per foot }\end{array}$ & $\begin{array}{l}\text { Each run } \\
246 \mathrm{~W}\end{array}$ & $\begin{array}{l}\text { ModaLight Super Flex-White FPCB- } \\
3000 \mathrm{~K}-\text { Warm White- } 115^{\circ} \text {, run lengths } \\
41^{\prime}-4^{\prime \prime} . \text { MP41 Dimmable Driver with DC } \\
\text { output to strips. Feeds, ends, and } \\
\text { connectors as required for complete } \\
\text { system. }\end{array}$ \\
\hline \multirow[b]{2}{*}{$\mathrm{CH} 1$} & \multirow[b]{2}{*}{ Large Decorative Chandelier } & \multirow[b]{2}{*}{$120 \mathrm{~V}$} & \begin{tabular}{|c|} 
(12) 12.5 W Philips LED A19, \\
$2700^{\circ} \mathrm{K}$ (supplied by contractor)
\end{tabular} & $\begin{array}{l}\text { 150W per } \\
\text { chandelier }\end{array}$ & \multirow{2}{*}{$\begin{array}{l}\text { St. Louis Antique Lighting Co. custom } \\
\text { chandelier, with twelve white glass } \\
\text { decorative globes. CD-7064-12. See cut } \\
\text { sheet for details. Drivers for amber rings } \\
\text { integrated into chandelier. }\end{array}$} \\
\hline & & & $\begin{array}{c}\text { (12) 2.1W Super Bright } \\
\text { LEDs.com LED ring, } 1200^{\circ} \mathrm{K} \\
\text { Amber (integral to chandelier) } \\
\end{array}$ & $\begin{array}{l}25.2 \mathrm{~W} \text { per } \\
\text { chandelier }\end{array}$ & \\
\hline \multirow[b]{2}{*}{$\mathrm{CH} 2$} & \multirow[b]{2}{*}{$\begin{array}{l}\text { Medium Decorative } \\
\text { Chandelier }\end{array}$} & \multirow[b]{2}{*}{$120 \mathrm{~V}$} & \begin{tabular}{|c|} 
(6) $12.5 \mathrm{~W}$ Philips LED A19, \\
$2700^{\circ} \mathrm{K}$ (supplied by contractor) \\
\end{tabular} & $75 \mathrm{~W}$ & \multirow{2}{*}{$\begin{array}{l}\text { St. Louis Antique Lighting Co. custom } \\
\text { chandelier, with six white glass } \\
\text { decorative globes. CD-7064-6 See cut } \\
\text { sheet for details. Drivers for amber rings } \\
\text { integrated into chandelier. }\end{array}$} \\
\hline & & & $\begin{array}{c}\text { (6) } 2.1 \mathrm{~W} \text { Super Bright } \\
\text { LEDs.com LED ring, } 1200^{\circ} \mathrm{K} \\
\text { Amber (integral to chandelier) } \\
\end{array}$ & $12.6 \mathrm{~W}$ & \\
\hline $\mathrm{T} 2$ & 2-Circuit Track-Black & $120 \mathrm{~V}$ & N/A & - & $\begin{array}{l}\text { Amerlux TEK412-BT-12'-2 (12' length) } \\
\text { Amerlux TEK412-BT-4'-2 (4' length) } \\
\text { Track runs, feed, ends, connectors, } \\
\text { and canopies as needed to provide } \\
\text { complete system. }\end{array}$ \\
\hline T4 & $\begin{array}{l}\text { PAR38 Trackhead-Black } \\
\text { 2-Circuit, for track Type T2 }\end{array}$ & $120 \mathrm{~V}$ & \begin{tabular}{|} 
LED PAR38 Replacement Lamp \\
Philips Enduraled PAR38 LED \\
$16 \mathrm{~W} 10^{\circ}$ or \\
$25^{\circ}$, as determined by Lighting \\
Designer
\end{tabular} & $16 \mathrm{~W}$ & $\begin{array}{l}\text { Amerlux TBI-250-PAR38-BT-TEK-120- } \\
\text { LESS LAMP }\end{array}$ \\
\hline
\end{tabular}





\section{Appendix D: Burden Museum Interior Luminaire Schedule for the Collection/Storage Room}

\begin{tabular}{|c|l|c|c|c|c|}
\hline \multicolumn{5}{|c|}{ COLLECTION/ STORAGE ROOM } \\
\hline Type & Description & Volt & Lamp & $\begin{array}{c}\text { Max } \\
\text { Watts }\end{array}$ & \multicolumn{1}{c|}{ Manufacturer } \\
\hline T7 & 1-Circuit Track-White & $120 \mathrm{~V}$ & N/A & $\begin{array}{l}\text { Amerlux GES208-WH-8'-1 (8' length) } \\
\text { wit feeds, connectors, and ends } \\
\text { required for complete system. }\end{array}$ \\
\hline T8 & $\begin{array}{l}\text { Integral LED track head for } \\
\text { Track Type T7. 3000K } \\
\text { (warm) color LED. White } \\
\text { track head finish. }\end{array}$ & $120 \mathrm{~V}$ & $\begin{array}{l}\text { LED and driver integral to track } \\
\text { head }\end{array}$ & 24W & $\begin{array}{l}\text { Amerlux Contour Vertical 3×3 track } \\
\text { head. CNTRV33-24-LED-E-WT-TNI-120- } \\
\text { MFL-3000 }\end{array}$ \\
\hline
\end{tabular}



Appendix E: Burden Museum Dimming Compatibility Documents 


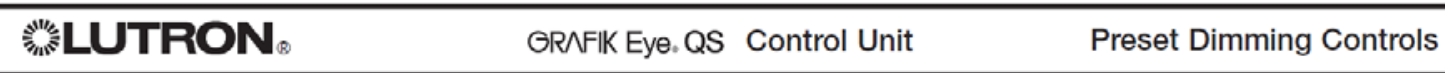

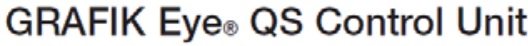
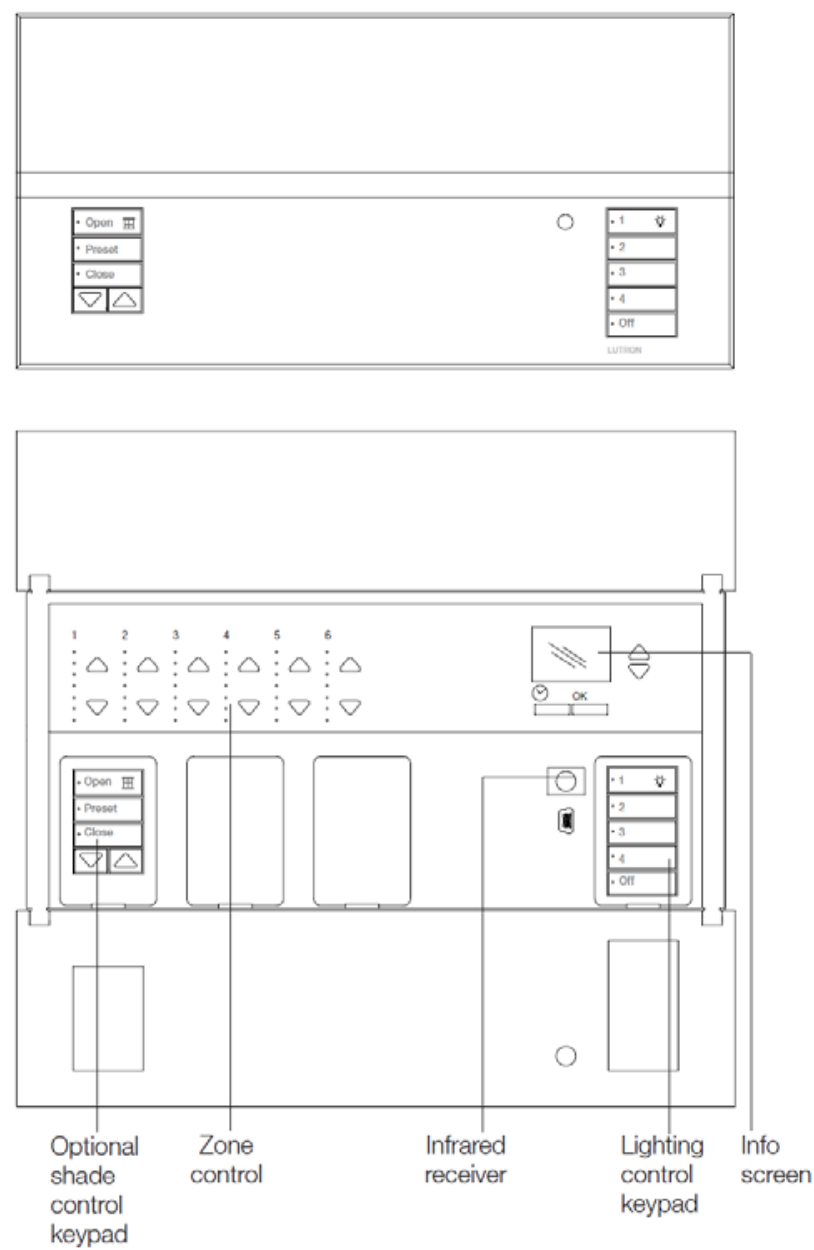

Description

- Provides pushbutton recall of four preset lighting scenes, plus Off.

- Offers optional integrated shade control buttons, which can be added to the unit after installation.

- Includes master override buttons to temporarily raise and lower all lights.

- Allows setup of lighting scenes and shade presets using buttons on the control unit.

- Controls many light source types directly and others using power interfaces.

- Provides individual control of light sources.

- Includes built-in infrared receiver.

- Includes external IR connection.

- Includes built-in astronomic timeclock.

- Provides info screen for zone light level percentage, energy savings, zone labeling, accessing additional scenes, programming, and timeclock scheduling.

- Info screen is language-selectable.

- Provides lockout options to prevent accidental changes.

- Includes one occupant sensor input and $24 \mathrm{~V}=$ = power for occupant sensors or other building management systems.

- Includes communication link for seamless integration of lights, motorized window treatments, and control stations.

- Backlit buttons with optional engraving make unit easy to find and to operate.

- Available in a variety of colors and finishes to match any decor.

- Compatible with all Lutron QS system components.

Note: General Engraving (-EGN) shown.

औLUTRON. SPECIFICATION SUBMITTAL

Figure E.1. Lutron Grafik Eye QSG spec sheet for control system used in Burden Museum, page 1 of 2. 


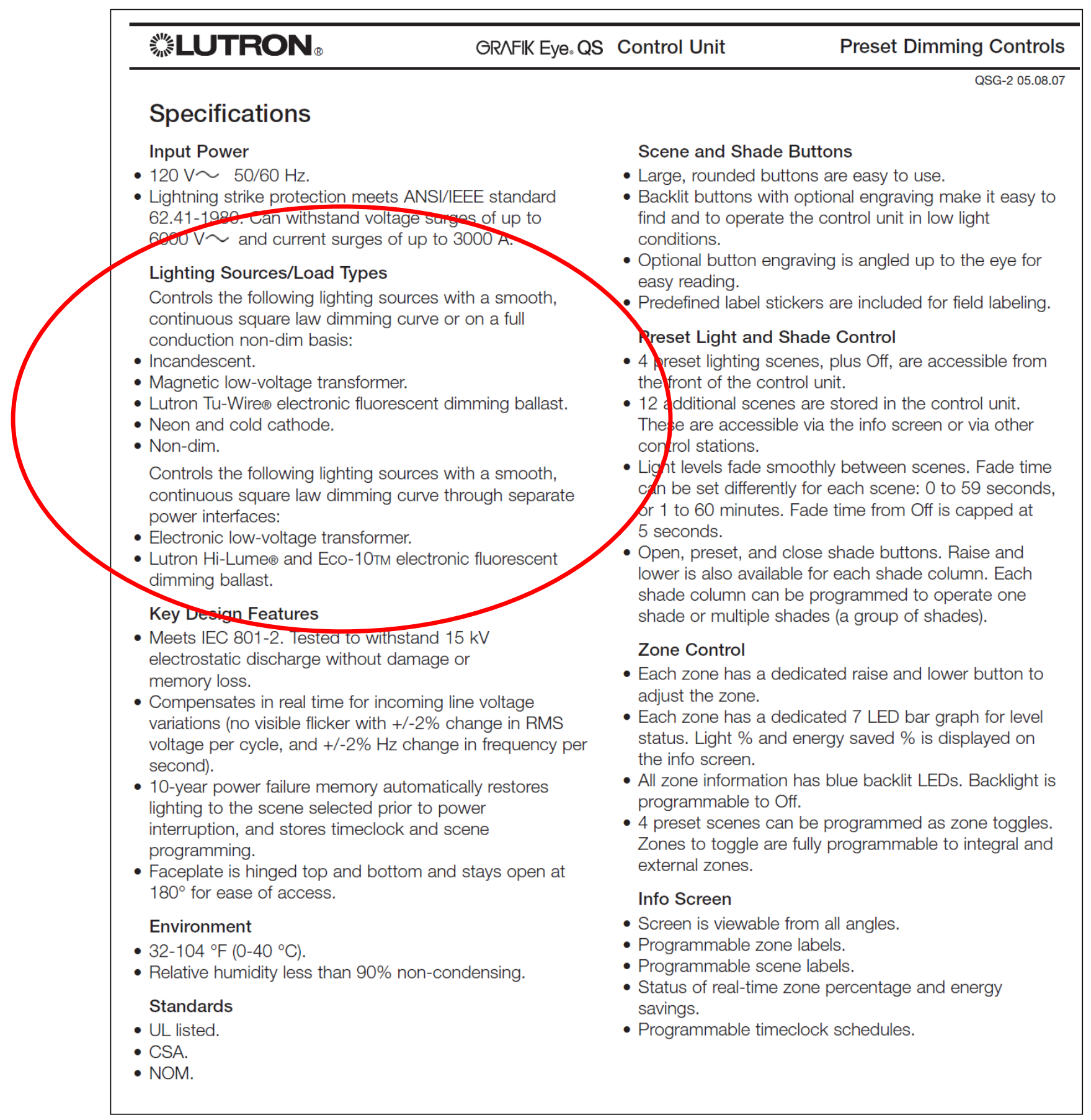

Figure E.2. Lutron Grafik Eye QSG spec sheet for control system used in Burden Museum, page 2 of 2. 


\begin{tabular}{|c|c|c|c|c|c|c|c|}
\hline \multirow{2}{*}{$\begin{array}{l}\text { PSC-1 } \\
\frac{\text { Control }}{\text { Zone }} \\
\underline{\text { Number }}\end{array}$} & \multicolumn{7}{|c|}{ Museum Main Hall and Entry Hall, Track Lighting } \\
\hline & Zone Lighting Description & $\begin{array}{c}\text { Eixture } \\
\text { Type }\end{array}$ & $\begin{array}{l}\text { Eixture } \\
\text { Quantity }\end{array}$ & $\begin{array}{c}\text { Eixure Load } \\
\text { Type }\end{array}$ & $\begin{array}{c}\frac{\text { Maximum }}{\text { Watts per }} \\
\underline{\text { Track Head }}\end{array}$ & $\begin{array}{l}\frac{\text { Total }}{\text { Zone }} \\
\underline{\text { Watts }}\end{array}$ & $\underline{\text { Remarks }}$ \\
\hline 1 & Track accent 1 - Entry Hall & $\mathrm{T} 4$ & 9 & \multirow{6}{*}{$\begin{array}{c}\text { LED integral } \\
\text { lamps for } \\
\text { Forward Phase } \\
\text { Incandescent } \\
\text { Dimmer } \\
\end{array}$} & 16 & 144 & \multirow{6}{*}{$\begin{array}{c}\text { Dimming mfg } \\
\text { recommends } 1 \\
\text { to } 14 \text { lamps per } \\
\text { dimmer, smooth } \\
\text { dimming down } \\
\text { to } 2 \% \\
\end{array}$} \\
\hline 2 & Track accent 2 - Entry Hall & $\mathrm{T} 4$ & 9 & & 16 & 144 & \\
\hline 3 & Track accent 1 - West & $\mathrm{T} 4$ & 9 & & 16 & 144 & \\
\hline 4 & Track accent 2 - West & $\mathrm{T} 4$ & 11 & & 16 & 176 & \\
\hline 5 & Track accent 1 - East & $\mathrm{T} 4$ & 11 & & 16 & 176 & \\
\hline 6 & Track accent 2 - East & $\mathrm{T} 4$ & 9 & & 16 & 144 & \\
\hline & & & & \multicolumn{2}{|c|}{ TOTAL LOAD (WATTS) } & 928 & \\
\hline
\end{tabular}

\begin{tabular}{|c|c|c|c|c|c|c|c|}
\hline \multirow{2}{*}{$\begin{array}{c}\text { PSC-2 } \\
\frac{\text { Control }}{\text { Zone }} \\
\text { Number }\end{array}$} & \multicolumn{7}{|c|}{ Museum Main Hall and Entry Hall, Cove \& Chandelier Lighting } \\
\hline & Zone Lighting Description & $\frac{\text { Fixture }}{\text { Type }}$ & $\frac{\text { Fixture }}{\text { Quantity }}$ & $\frac{\text { Fixure Load }}{\text { Type }}$ & $\begin{array}{l}\text { Maximum } \\
\text { Watts per } \\
\text { Track Head }\end{array}$ & $\begin{array}{l}\text { Total } \\
\text { Zone } \\
\text { Watts }\end{array}$ & Remarks \\
\hline 1 & Large Chandelier General Lighting & $\mathrm{CH} 1$ & 12 & \begin{tabular}{|c|} 
LED for Forward \\
Phase INC \\
dimmer
\end{tabular} & 12.5 & 150 & $\begin{array}{l}\text { (1) PHPM-PA-120 } \\
\text { interface req. }\end{array}$ \\
\hline 2 & $\begin{array}{l}\text { Large Chandelier Simulated Gas } \\
\text { Ltg }\end{array}$ & $\mathrm{CH} 1$ & 12 & LED - Non-Dim & 2.1 & 25.2 & \\
\hline 3 & $\begin{array}{l}\text { Medium Chandelier General } \\
\text { Lighting }\end{array}$ & $\mathrm{CH} 2$ & 12 & \begin{tabular}{|c|} 
LED for Forward \\
Phase INC \\
dimmer
\end{tabular} & 12.5 & 150 & $\begin{array}{l}\text { (1) PHPM-PA-120 } \\
\text { interface req. }\end{array}$ \\
\hline 4 & $\begin{array}{l}\text { Medium Chandelier Simulated Gas } \\
\text { Ltg }\end{array}$ & $\mathrm{CH} 2$ & 12 & LED - Non-Dim & 2.1 & 25.2 & \\
\hline 5 & $\begin{array}{l}\text { Upper Cove Lighting,41' run,246W } \\
\text { each }\end{array}$ & L2 & 2 & $\begin{array}{l}\text { LED for MLV } \\
\text { dimmer }\end{array}$ & 246 & 492 & $\begin{array}{l}\text { (1) PHPM-PA-120 } \\
\text { interface req. }\end{array}$ \\
\hline \multirow[t]{2}{*}{6} & $\begin{array}{l}\text { Lower Cove Lighting,41' run,246W } \\
\text { each }\end{array}$ & L2 & 2 & $\begin{array}{l}\text { LED for MLV } \\
\text { dimmer }\end{array}$ & 246 & 492 & $\begin{array}{l}\text { (1) PHPM-PA-120 } \\
\text { interface req. }\end{array}$ \\
\hline & & & & \multicolumn{2}{|c|}{ TOTAL LOAD (WATTS) } & 1,334 & \\
\hline
\end{tabular}

Figure E.3. Dimming schedule for Museum Entry Hall and Main Hall. 


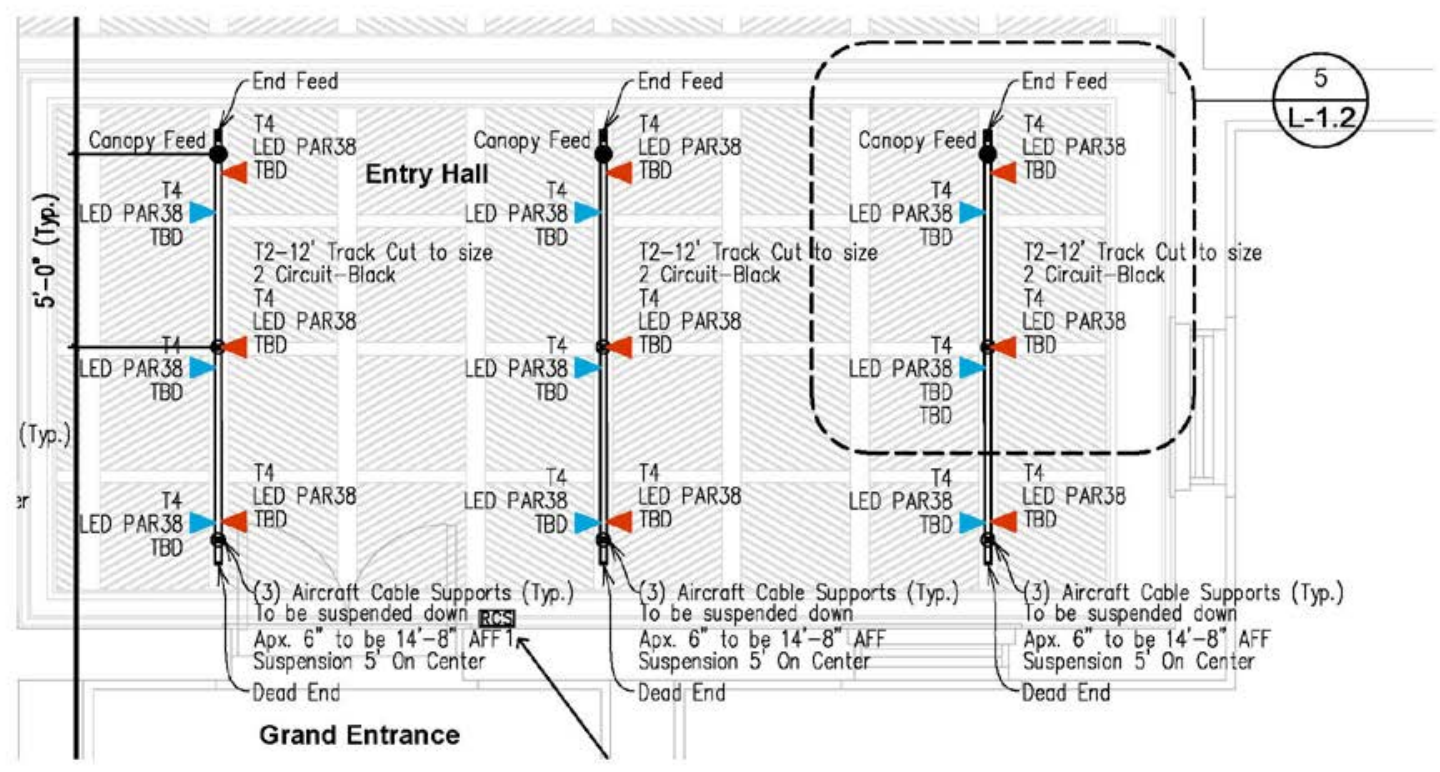

Figure E.4. Enlarged Entry Hall lighting plan showing track lighting for control zones 1 and 2 of PSC-1.

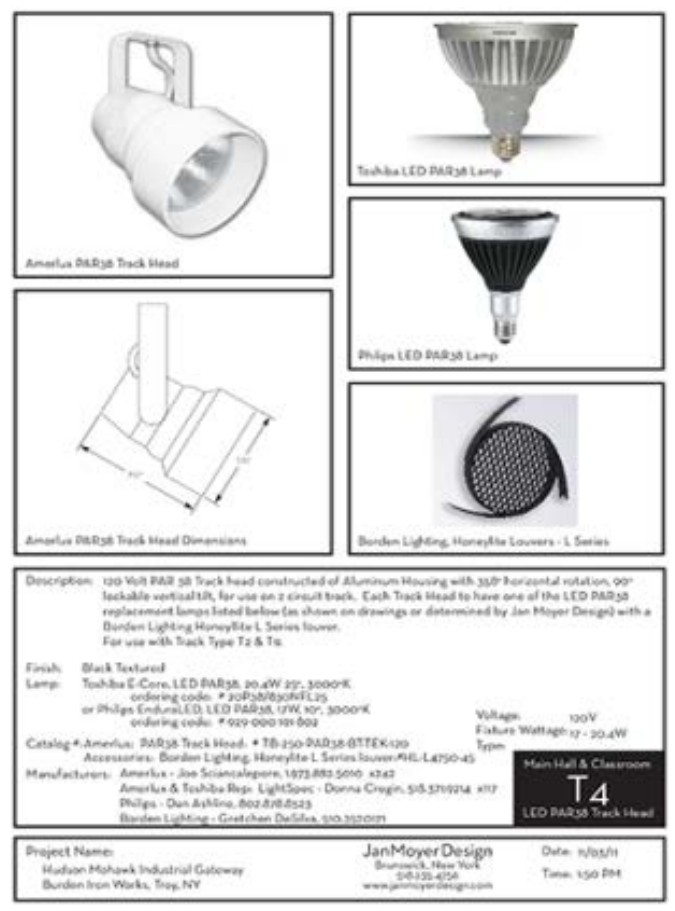

Figure E.5. Track head T4, using LED PAR38 lamp. 


\begin{tabular}{|c|c|c|c|c|c|c|c|c|c|c|}
\hline Item & Brand & Series & ID & Load & Type & $\begin{array}{l}\text { Dimming level } \\
\text { Max.>Min. } \\
\text { (flux\%) } \\
\text { I lamp }\end{array}$ & $\begin{array}{l}\text { Flickering } \\
\text { I lamp }\end{array}$ & $\begin{array}{l}\text { Flickering } \\
3 \text { lamps }\end{array}$ & $\begin{array}{l}\text { Flickering } \\
5 \text { lamps }\end{array}$ & $\begin{array}{l}\text { Flickering } \\
8 \text { lamps }\end{array}$ \\
\hline I & LEVITON & Decora & 6161 & $500 \mathrm{~W}$ & LE & $99 \%-0$ & No & No & No & No \\
\hline 2 & LEVITON & Trimatron & 6684 & $600 \mathrm{~W}$ & LE & $100 \%-0$ & No & No & at $\sim 40 \%$ & at $\sim 40 \%$ \\
\hline 3 & LEVITON & SureSlide & 6613 & $600 \mathrm{~W}$ & LE & $100 \%-2 \%$ & No & No & No & No \\
\hline 4 & LEVITON & Illumatech & IPI06-IL & $600 \mathrm{~W}$ & LE & $100 \%-9 \%$ & No & at $\sim 60 \%$ & $\sim 40 \%-50 \%$ & $\sim 0 \%-40 \%$ \\
\hline 5 & LUTRON & Ariadni & $A Y-600 P$ & $600 \mathrm{~W}$ & LE & $100 \%-5 \%$ & No & No & No & No \\
\hline 6 & LUTRON & Diva & DV-600P & $600 \mathrm{~W}$ & LE & $99 \%-2 \%$ & No & No & No & at $\sim 70 \%$ \\
\hline 7 & LUTRON & Diva & DVPDC $-203 P$ & $200 \mathrm{~W}$ & LE & $99 \%-29 \%$ & No & $\sim 0-50 \%$ & no dimmability & no dimmability \\
\hline 8 & LUTRON & Glyder & GL-600 & $600 \mathrm{~W}$ & LE & $100 \%-2 \%$ & No & No & No & No \\
\hline 9 & LUTRON & NOVA & NLV-1000 & $1000 \mathrm{~W}$ & LE & $100 \%-3 \%$ & No & No & No & No \\
\hline 10 & LUTRON & Qoto & Q-600P & $600 \mathrm{~W}$ & LE & $100 \%-4 \%$ & No & No & No & at $\sim 70 \%$ \\
\hline 11 & LUTRON & Skylark & S-600P & $600 \mathrm{~W}$ & LE & $90 \%-3 \%$ & No & No & No & at $\sim 80 \%$ \\
\hline 12 & LUTRON & Toggler & TG-600P & $600 \mathrm{~W}$ & LE & $100 \%-5 \%$ & No & No & No & at $\sim 70 \%$ \\
\hline 13 & LUTRON & Credenza & Tा-300 & $300 \mathrm{~W}$ & LE & $100 \%-0$ & No & No & No & at $\sim 40 \%$ \\
\hline
\end{tabular}

Figure E.6. Philips PAR38 LED compatible dimmer list, which does not show architectural dimming systems. 


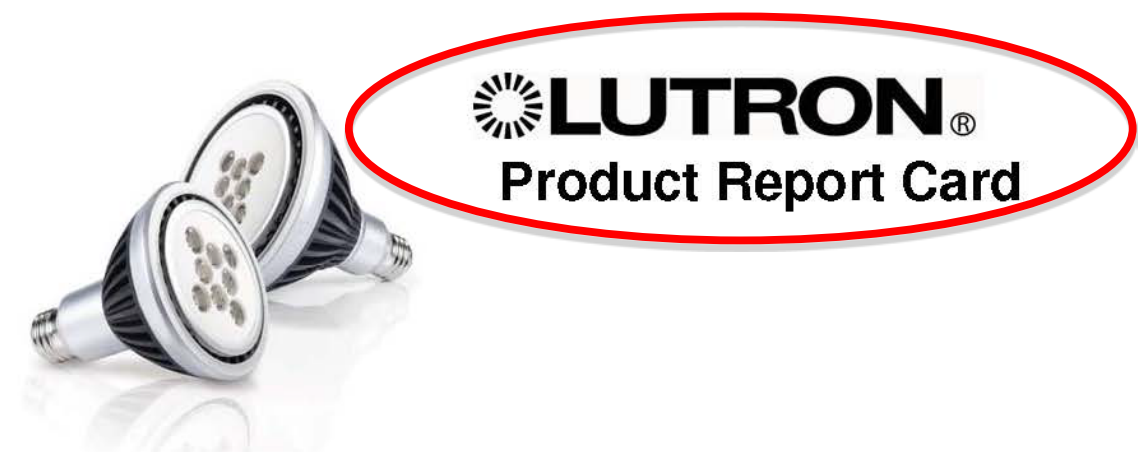

Manufacturer: $\quad$ Phillips

Applicable Model Numbers: 92900017 1200/1300/1400

Manufacturer's Description

Type of Fixture: PAR38 Indoor Flood

Operating Voltage: $120 \mathrm{VAC}$

Input Power: $\quad 16 \mathrm{~W}$

Current: $\quad 185 \mathrm{~mA}$

Frequency: $\quad 60 \mathrm{~Hz}$

Control Types: Not Specified

Dimming Range: Not Specified

Equivalent Incandescent Output Power: 45 W

Lumens: $\quad 650 \mathrm{~lm}(3000 \mathrm{~K})$

Lutron Test Results

Date Tested:

May 4, 2010

Model Number Tested: $\quad$ EnduraLED PAR38 dimmable $120 \mathrm{~V} 16 \mathrm{~W}$

Smooth and Continuous: Yes

Test Notes: None

\section{Lutron Recommended Compatible Products}

\begin{tabular}{|c|c|c|c|c|}
\hline Product & Part Number & $\begin{array}{c}\begin{array}{c}\text { Fixtures } \\
\text { per } \\
\text { Dimmer }\end{array} \\
\end{array}$ & $\begin{array}{l}\text { Measured } \\
\text { Light Output } \\
\text { Range }^{(1)}\end{array}$ & Comments \\
\hline RadioRA 2 & RRD-10ND & $1-16$ & $4 \%-100 \%$ & Smooth and continuous \\
\hline \multirow[t]{4}{*}{ Homeworks } & HWD-5NE & $1-7$ & $3 \%-100 \%$ & Smooth and continuous \\
\hline & HWD-6NE & $1-9$ & $17 \%-100 \%$ & Smooth and continuous \\
\hline & HW-RPM-4A-120 & 110 & $20 / 100 \%$ & Smooth and continuous \\
\hline & & per output & & Maximum of 29 ixtures \\
\hline \multirow[t]{3}{*}{$\begin{array}{l}\text { Commercial } \\
\text { Systems }\end{array}$} & QSG-6P & $\begin{array}{c}1-14 \\
\text { per output }\end{array}$ & $2 \%-100 \%$ & $\begin{array}{l}\text { Smooth and continuous } \\
\text { Maximum of } 35 \text { fixtures }\end{array}$ \\
\hline & L_R_RPM-4A-120 & $1-18$ & $8 \%-100 \%$ & Smooth and somtinuous \\
\hline & & per output & & Maximum of 29 fixtures \\
\hline Interfaces & PHPM-WBX & $1-29$ & $7 \%-100 \%$ & Smooth and continuous \\
\hline
\end{tabular}

Comments: Some dimmers may require a low-end trim adjustment. The ability to set the low-end trim is available on select 3-Wire Fluorescent dimmers, Homeworks, and Commercial Systems products. Refer to product documentation or www. lutron.com for details.

Figure E.7. Lutron report card for Philips 16W Enduraled PAR38 lamp. This indicates the Lutron QSG6P dimmer can control between 1 and 14 lamps per dimming zone, and the lamp output can be dimmed to $2 \%$ of maximum output. 

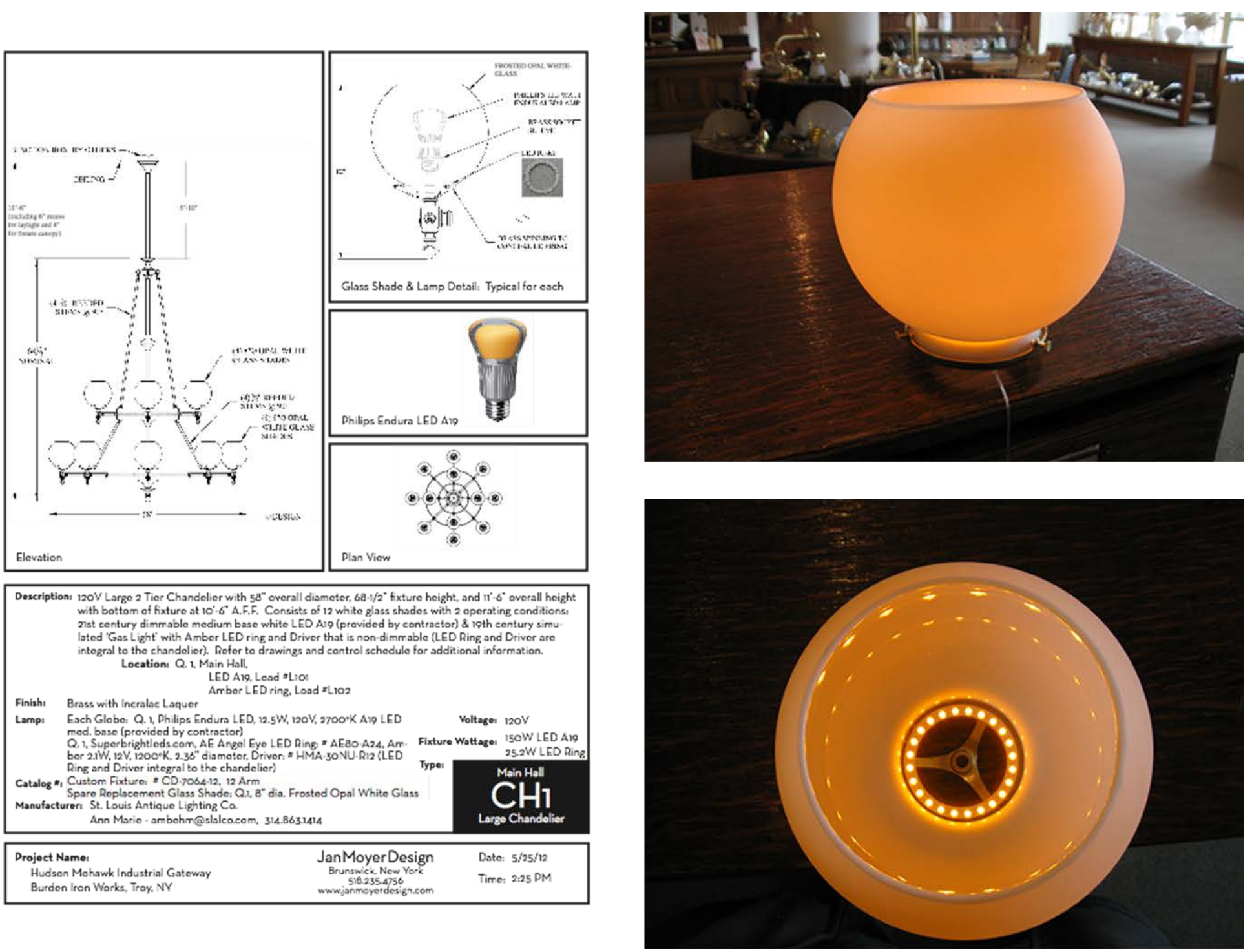

Figure E.8. Burden Museum Main Hall chandelier details, showing LED A19 lamp and amber LED ring. 


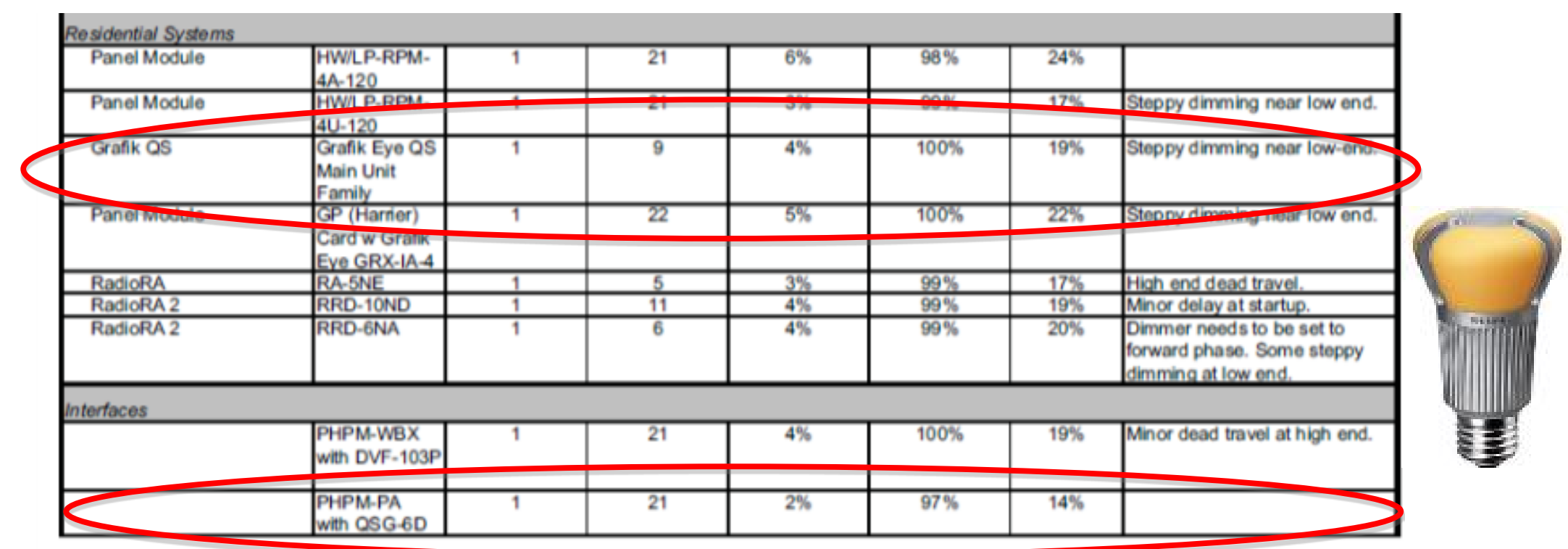

Figure E.9. Philips Enduraled A-lamp dimming compatibility report, showing maximum number of lamps recommended per zone is 9 for Grafik Eye QS dimming zone, and 21 for PHPM-PA interface (Phase Adaptive Power Module). 


\section{Phase-Adaptive Power Module}

\section{Description}

- Provides capability for a zone on a GRAFIK Eye control unit (or other product) to dim a fully loaded circuit of lighting.

- May be used to control incandescent, electronic low-voltage, magnetic low-voltage, and neon/ cold cathode lighting sources, as well as Lutron. Tu-Wire fluorescent dimming ballasts.

- Automatically selects leading-edge or trailing-edge dimming for low-voltage transformers.

- Provides power and dimming for one zone.

- Up to 3 power modules may be wired on a single GRAFIK Eye• zone.

- Models available for $120 \mathrm{~V} \sim$ control power.

- Models available for 120 V or 120 - 277 V

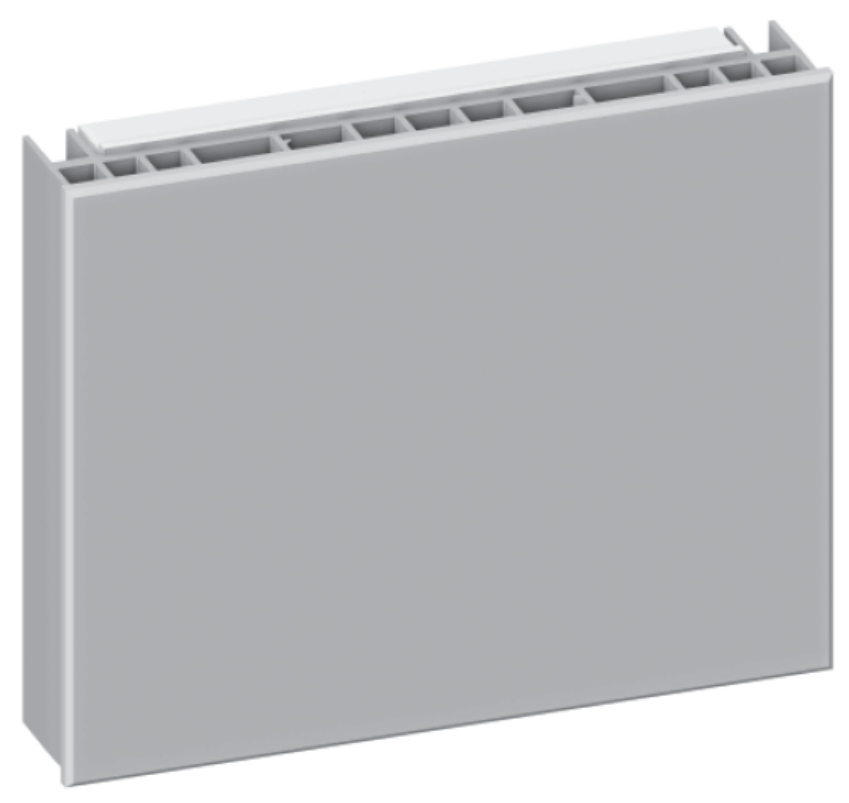

load power.

- Not for use with non-dim loads.

Works with $120 \mathrm{~V} \sim$ versions of:

- GRAFIK Eye. QS control units*

Figure E.10. A phase-adaptive power module that effectively increases the load that a dimming zone can control, to be used when the number of LED lamps on a dimming zone exceeds the dimming report's recommended maximum number. 


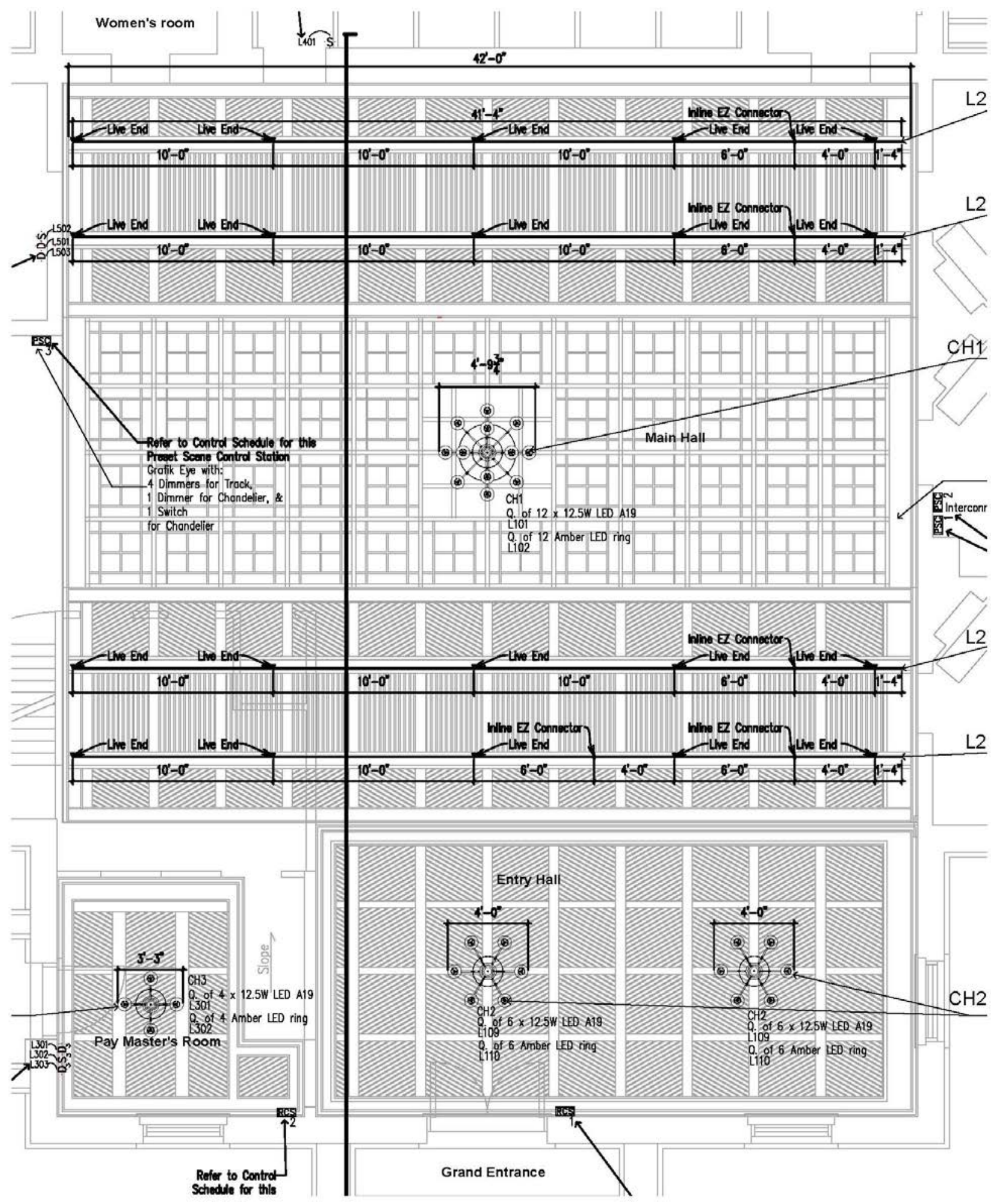

Figure E.11. Enlarged plan of chandeliers and cove lighting in Main Hall and Entry. 


\section{MOdaLIGHT}

S P E C I F I C A T I O N
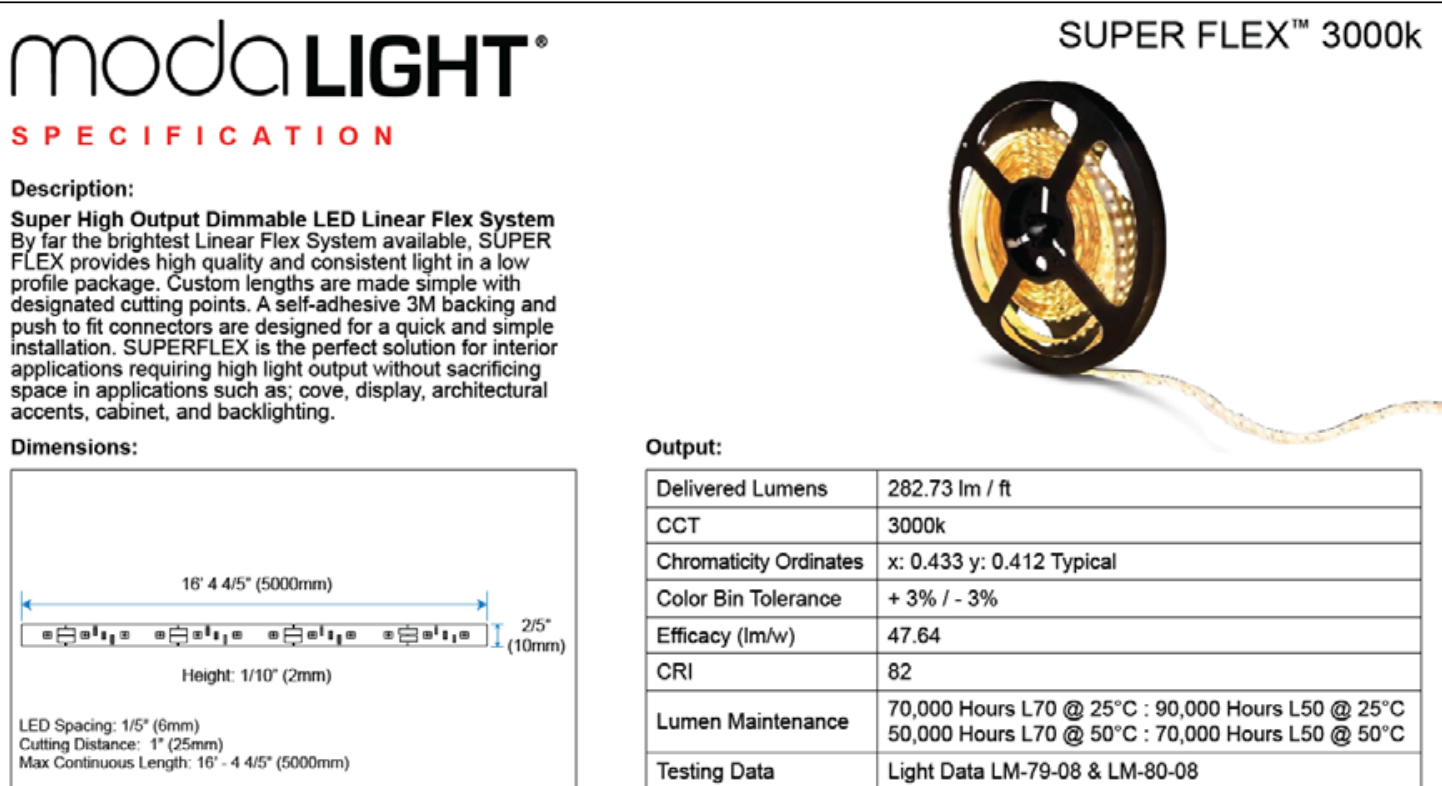

\begin{tabular}{|l|l|}
\hline Delivered Lumens & $282.73 \mathrm{Im} / \mathrm{ft}$ \\
\hline CCT & $3000 \mathrm{k}$ \\
\hline Chromaticity Ordinates & $\mathrm{x}: 0.433 \mathrm{y}: 0.412$ Typical \\
\hline Color Bin Tolerance & $+3 \% /-3 \%$ \\
\hline Efficacy (Im/w) & 47.64 \\
\hline CRI & 82 \\
\hline Lumen Maintenance & $\begin{array}{l}70,000 \text { Hours L70 @ } 25^{\circ} \mathrm{C}: 90,000 \text { Hours L50 @ } 25^{\circ} \mathrm{C} \\
50,000 \text { Hours L70 @ } 50^{\circ} \mathrm{C}: 70,000 \text { Hours L50 @ } 50^{\circ} \mathrm{C}\end{array}$ \\
\hline Testing Data & Light Data LM-79-08 \& LM-80-08 \\
\hline
\end{tabular}

Illuminance at a Distance: Data Shown for $113^{\circ}$ (For lux multiply fc by 10.7)
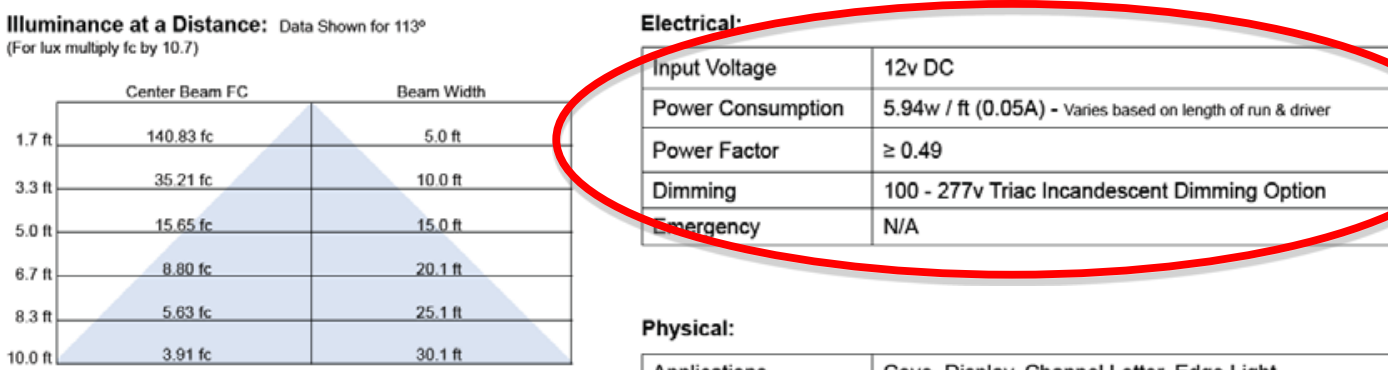

\begin{tabular}{|l|l|}
\hline Input Voltage & $12 \mathrm{v}$ DC \\
\hline Power Consumption & $5.94 \mathrm{w} / \mathrm{ft}(0.05 \mathrm{~A})$ - Vanies based on length of run \& driver \\
\hline Power Factor & $\geq 0.49$ \\
\hline Dimming & $100-277 v$ Triac Incandescent Dimming Option \\
\hline Smergency & N/A \\
\hline
\end{tabular}

—eam Spread: $112.8^{\circ}$

Polar Candela Distribution: Lumens per Zone: Data Shown for $113^{\circ}$

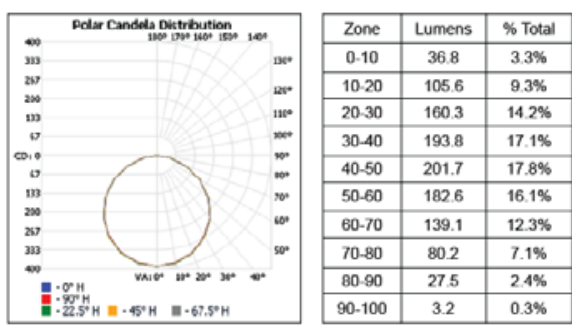

Physical:

\begin{tabular}{|l|l|}
\hline Applications & Cove, Display, Channel Letter, Edge Light \\
\hline Dimensions & $\begin{array}{l}\text { Length } 16^{\prime}-44 / 5^{\prime \prime}(5000 \mathrm{~mm}) \\
\text { Width } 2 / 5^{\prime \prime}(10 \mathrm{~mm}) \\
\text { Height } 1 / 10^{\prime \prime}(2 \mathrm{~mm})\end{array}$ \\
\hline Weight & 6.4 oz $(181.4 \mathrm{~g})$ Per Reel \\
\hline Construction & $\begin{array}{l}\text { Intelli-IC }{ }^{\mathrm{TM}} \text { Constant Voltage Design Protects LEDs And } \\
\text { Prolongs Life. White FPCB }\end{array}$ \\
\hline Thermal Management & N/A \\
\hline Optics & N/A \\
\hline Fixture Connections & Push To Fit Connectors \\
\hline Operating Temperature & $-40^{\circ} \mathrm{F} \sim 122^{\circ} \mathrm{F}\left(-40^{\circ} \mathrm{C} \sim 80^{\circ} \mathrm{C}\right)$ \\
\hline Storage Temperature & $-40^{\circ} \mathrm{F} \sim 212^{\circ} \mathrm{F}\left(-40^{\circ} \mathrm{C} \sim 100^{\circ} \mathrm{C}\right)$ \\
\hline Humidity & $0-95 \%$ Non Condensing \\
\hline
\end{tabular}

\begin{tabular}{|l|l|}
\hline Project Name: & Date: \\
\hline Company: & P/O \# \\
\hline Name: & Type: \\
\hline Notes: & \\
\hline
\end{tabular}

Standards and Certifications:

\begin{tabular}{|l|l|}
\hline Certification & $\begin{array}{l}\text { Tested to UL \& CSA by ETL For Use in USA } \\
\text { \& CANADA, Complies with California Title 24 } \\
\text { Requirements, Lighting Facts, CE \& RoHS Compliant }\end{array}$ \\
\hline Class & Class III \\
\hline Environment & Dry Location - IP20 \\
\hline Warranty & 2 Year Limited Warranty \\
\hline
\end{tabular}

VDC20100804

(C) Copyright $2011 \cdot 955$ White Drive, Las Vegas, NV 89119 • T: $7024077775 \cdot$ F: $7024077773 \cdot$ www.modalight.com

Figure E.12. MODA LIGHT linear LED strips used in cove lights. Notice it uses a remote magnetic transformer. The driver is built into the LED boards themselves. 


\section{Accessories:}

\begin{tabular}{|c|c|c|c|c|c|}
\hline & & 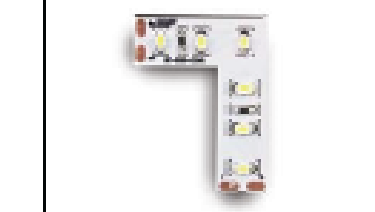 & 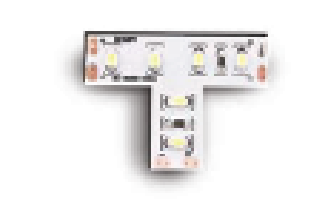 & & \\
\hline $\begin{array}{l}\text { MRTA35 } \\
\text { Live End }\end{array}$ & $\begin{array}{l}\text { MRTA34 } \\
\text { EZ-Connector }\end{array}$ & $\begin{array}{l}\text { MRTA31 } \\
\text { L-Bend Connector }\end{array}$ & $\begin{array}{l}\text { MRTA33 } \\
\text { T-Bend Connector }\end{array}$ & $\begin{array}{l}\text { MP16 } \\
12 v \text { DC } 132 w\end{array}$ & $\begin{array}{l}\text { MP41 } \\
12 v / 24 v \text { DC } 60 w\end{array}$ \\
\hline $\begin{array}{l}\text { Connects SUPERFLEX to } \\
\text { Power Supply }\end{array}$ & $\begin{array}{l}\text { Connects } 2 \text { SUPERFLEX } \\
\text { Together }\end{array}$ & $\begin{array}{l}\text { L-Shaped Bend for } \\
\text { Connecting } 2 \text { SUPERFLEX } \\
\text { Together }\end{array}$ & $\begin{array}{l}\text { T-Shaped Bend for } \\
\text { Connecting } 3 \text { SUPERFLEX } \\
\text { Together }\end{array}$ & $\begin{array}{l}\text { 132w 12v DC LED } \\
\text { Power Supply }\end{array}$ & $\begin{array}{l}\text { 60w } 12 \mathrm{v} \text { and } 24 \mathrm{v} \text { DC LED } \\
\text { Power Supply }\end{array}$ \\
\hline \multirow[t]{2}{*}{$\begin{array}{l}\text { L: } 10^{\circ}(3048 \mathrm{~mm}) \\
\text { W. } 3 / 5^{\circ}(15 \mathrm{~mm})\end{array}$} & \multirow{2}{*}{$\begin{array}{l}\text { L: }: 3 / 5^{\circ}(16 \mathrm{~mm}) \\
W: 1 / 5^{\circ}(5 \mathrm{~mm}) \\
\mathrm{H}: 1 / 10^{\circ}(2 \mathrm{~mm})\end{array}$} & \multirow[t]{2}{*}{$\begin{array}{l}\text { L: } 11 / 2(37 \mathrm{~mm}) \\
W: 11 / 10^{\circ}(28 \mathrm{~mm})\end{array}$} & \multirow[t]{2}{*}{$\begin{array}{l}\mathrm{L}: 12 / 5{ }^{\circ}(35 \mathrm{~mm}) \\
\mathrm{W}: 11 / 10^{\circ}(27 \mathrm{~mm})\end{array}$} & $\begin{array}{l}\text { Powers Up To } 22 \mathrm{ft} \\
\text { SUPERFLEX }\end{array}$ & $\begin{array}{l}\text { Powers Up To } 10 \mathrm{ft} \\
\text { SUPERFLEX }\end{array}$ \\
\hline & & & & Non-Dimmable & Dimmable \\
\hline \multicolumn{4}{|c|}{ Ordering Sample Number: SUPERFLEX-3000k } & \multirow{2}{*}{\multicolumn{2}{|c|}{ Ordering }} \\
\hline Product Name & Finish & Color Temp. & Beam Angle & & \\
\hline SUPERFLEX & White FPCB & $\begin{array}{l}\text { 3000k - Warm White } \\
\text { 6000k - Cool White }\end{array}$ & $\begin{array}{l}\text { «Special Order } \\
\text { Consult Factory }\end{array}$ & $\begin{array}{l}\text { MRTA35 } \\
\text { MRTA34 } \\
\text { MRTA31 3000k } \\
\text { MRTA33 3000k }\end{array}$ & $\begin{array}{l}\text { MP16 } \\
\text { MP41 }\end{array}$ \\
\hline
\end{tabular}

Minimum order quantity may apply. Due to continuous Improvements and innovations, specincations may change without notice. Please refer to our websile for current technical data. These fogures are provided as a guldellne only and may vary with differing power supplles and Installations. All rights reserved. E. \& O.E.

() Copyright 2011 • 955 White Drive, Las Vegas, NV 89119 • T: 7024077775 • F: $7024077773 \cdot$ www.modalight.com

Figure E.13. The power supply for this linear LED product is a magnetic transformer that delivers DC power to the LED strip. There is no compatibility issue with this type of product except to size the dimming zone for the maximum power of the transformer. 



\section{Appendix F: Burden Museum Storage Area Vault Dimming Documents}

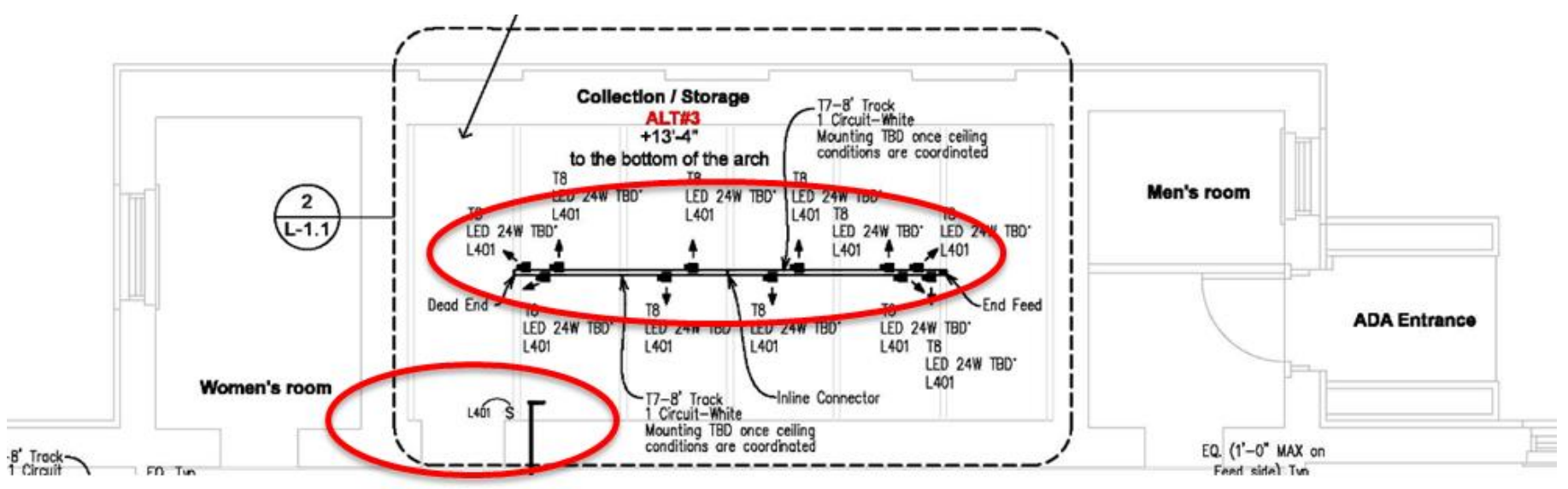

Figure F.1. Enlarged lighting plan of Storage Area/Vault, showing lighting and control. 


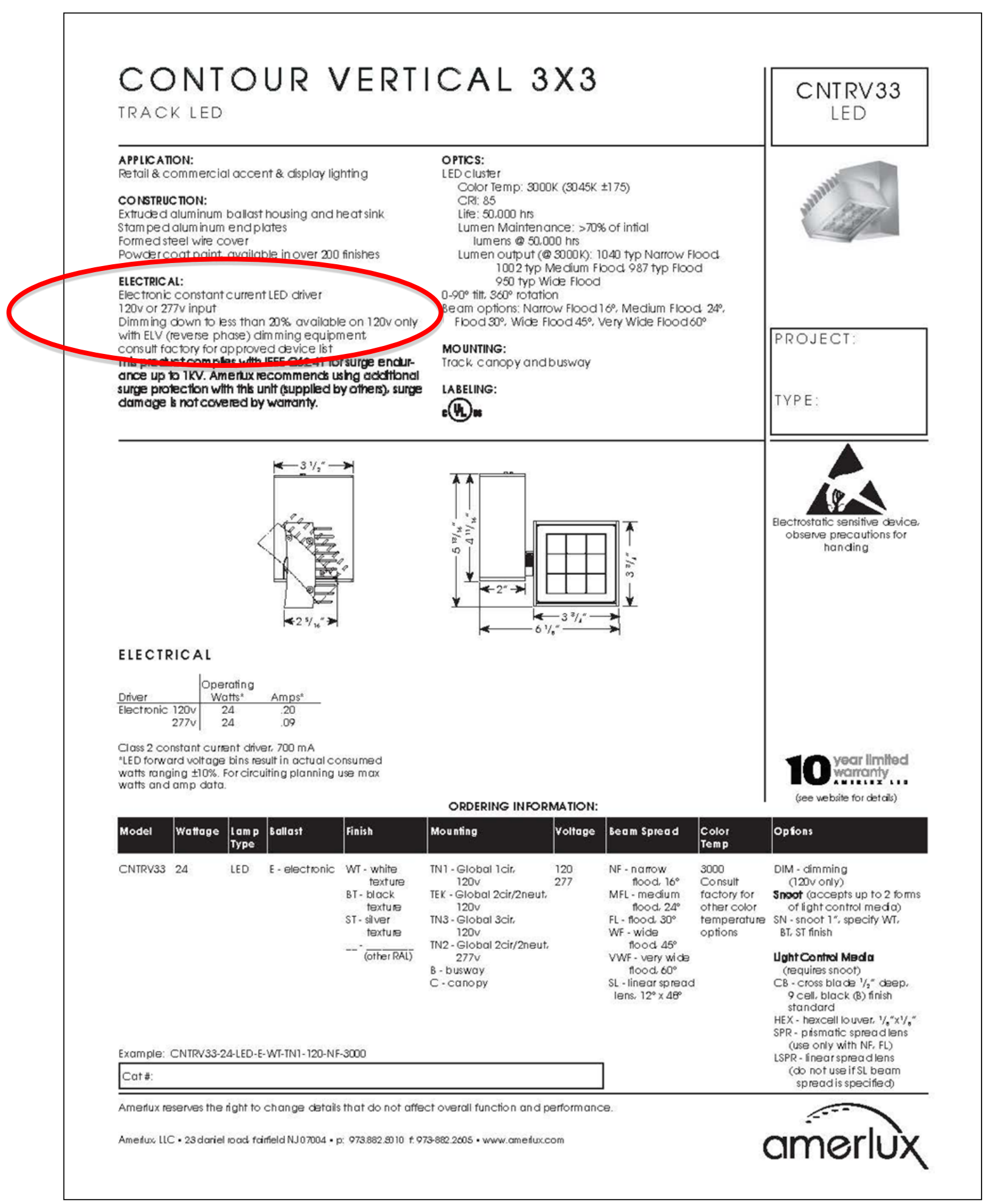

Figure F.2. Amerlux LED track head used in Museum storage room. Manufacturer recommends ELV (reverse phase) dimmer. However, the Lutron report card on the same product shows it to be compatible with a three-wire or Eco-system (fluorescent) wall-box dimmer (rather than an ELV dimmer), with a maximum number of 59 CNTRV-3X3 heads per dimmer. See Figure F.3. 


\section{热: LUTRON \\ Report Card \\ (For fixtures using the Lutron Hi-lume LED Driver)}

Manufacturer: Amerlux

Website: www.amerlux.com

Applicable Model Numbers: Contour Vertical

Date: October 2009

Fixture Manufacturer's Description

Type of Fixture: Downlight

Operating Voltage: $120 \mathrm{~V} / 277 \mathrm{~V}$

Control Types: 3 Wire/ EcoSystem

Dimming Range: $100 \%-1 \%$

Input Current (max.): $0.27 \mathrm{~A}(120 \mathrm{~V}) / 0.13 \mathrm{~A}(277 \mathrm{~V})$

Driver Manufacturer: Lutron Electronics

Product: Hi-Lume LED Driver

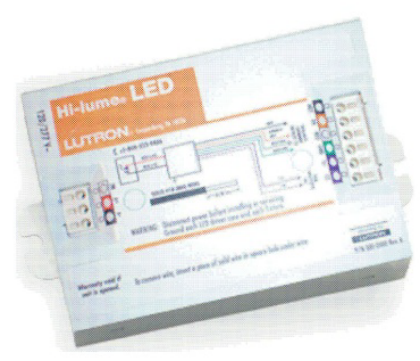

Compatible Lutron Products

\begin{tabular}{|c|c|c|c|c|}
\hline \multirow{2}{*}{ Product } & \multirow{2}{*}{ Part Number } & \multicolumn{2}{|c|}{ Fixtures per Dimmer } & \multirow{2}{*}{$\begin{array}{c}\text { Measured } \\
\text { Light Outpu } \\
\text { Range }\end{array}$} \\
\hline & & $120 \mathrm{~V}$ & $277 \mathrm{~V}$ & \\
\hline NovaT & NTF-10, & $1-59$ & - & $100 \%-1 \%$ \\
\hline NovaT & NTF-103P, NTF-10-277 & $1-29$ & $1-61$ & $100 \%-1 \%$ \\
\hline NovaT & NTF-103P-277 & - & $1-46$ & $100 \%-1 \%$ \\
\hline Nova & $\mathrm{NF}-10$ & $1-59$ & - & $100 \%-1 \%$ \\
\hline Nova & NF-103P, NF-10-277 & $1-29$ & $1-61$ & $100 \%-1 \%$ \\
\hline Nova & NF-103P-277 & - & $1-46$ & $100 \%-1 \%$ \\
\hline Vareo & VF-10 & $1-29$ & - & $100 \%-1 \%$ \\
\hline Skylark & SF-10P, SF-103P & $1-29$ & - & $100 \%-1 \%$ \\
\hline Skylark & SF-12P-277,SF-12P-277-3 & - & $1-46$ & $100 \%-1 \%$ \\
\hline Diva & DVF-103, DVSCF-103P & $1-29$ & - & $100 \%-1 \%$ \\
\hline Diva & DVF-103P-277,DVSCF-103P-277 & - & $1-46$ & $100 \%-1 \%$ \\
\hline Ariadni & AYF-103P & $1-29$ & - & $100 \%-1 \%$ \\
\hline Ariadni & AYF-103P-277 & - & $1-46$ & $100 \%-1 \%$ \\
\hline Vierti & VTF-6AM & $1-22$ & - & $100 \%-1 \%$ \\
\hline Maestro & $\begin{array}{c}\text { MAF-6AM, MAF-6AM-277, MSCF- } \\
\text { 6AM, MCSF-6AM-277 }\end{array}$ & $1-22$ & $1-46$ & $100 \%-1 \%$ \\
\hline Maestro Wireless & MRF2-F6AN-DV & $1-22$ & $1-46$ & $100 \%-1 \%$ \\
\hline Spacer System & $\begin{array}{c}\text { SPSF-6A,SPSF-6A-277, SPSF- } \\
\text { 6AM, SPSF-6AM-277 }\end{array}$ & $1-22$ & $1-46$ & $100 \%-1 \%$ \\
\hline Lyneo & LXF-103PL & $1-29$ & - & $100 \%-1 \%$ \\
\hline Lyneo & LXF-103PL-277 & - & $1-46$ & $100 \%-1 \%$ \\
\hline \multirow[t]{2}{*}{ Interfaces $^{(1)}$} & PHPM-3F & $1-59$ & $1-123$ & $100 \%-1 \%$ \\
\hline & GRX-FDBI-16A & $1-59$ & - & $100 \%-1 \%$ \\
\hline \multirow[t]{3}{*}{ EcoSystem } & $\begin{array}{l}\text { CS-1L-WM, CS-2L-WM, CS-1L- } \\
\text { CM, CS-2L-CM, EcoSystem ESN }\end{array}$ & \multicolumn{2}{|c|}{64 per EcoSystem link } & $100 \%-1 \%$ \\
\hline & Grafik Eye QS with EcoSystem & \multicolumn{2}{|c|}{64 per EcoSystem link } & $100 \%-1 \%$ \\
\hline & Quantum & \multicolumn{2}{|c|}{64 per EcoSystem link } & $100 \%-1 \%$ \\
\hline
\end{tabular}

(1) For use with 3 Wire controls or Commercial Systems, RA Systems or Home Systems applications

Figure F.3. Lutron dimming report card on Amerlux CNTRV track head. Note that although there is no specific listing of the Grafik Eye QSG product, all the other dimming listings suggest a fluorescent dimmer control signal. 
Radio $\mathbf{R A} 2$ product spectifications $360-2259$

04.18.11

\section{RadioRA 2 Maestro. Local Controls}

RadioRA 2 Maestro local controls function much like standard dimmers and switches, but can be controlled as part of a lighting control system. Local lighting controls are useful in locations where single circuits of lighting need to be dimmed or switched.

RadioRA 2 Maestro dimmers incorporate advanced features such as fade on/fade off, delayed long fade to off, and rapid full on.

RadioRA 2 Maestro local controls include a Front Accessible Service Switch (FASS TM $_{\text {) for safe }}$ lamp replacement. RadioRA 2 Maestro local controls install in single-pole or multi-location applications. Remote dimmers/switches are available for multi-location control.

Use Lutron» Designer (Claro» or Satin Colorsø) wallplates or designer-style wallplates from other manufacturers. Wallplates are sold separately. Lutron Claro and Satin Colors wallplates snap on with no visible means of attachment. RadioRA 2 Maestro local controls support color change kits.

\section{Model Numbers}

\section{Dimmers}

Incandescent/Halogen/MLV (120 V )

RRD-6D-XX* 600 W/600 VA Dimmer

RRD-10D-XX* 1000 W/1000 VA Dimmer

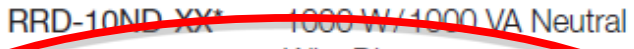

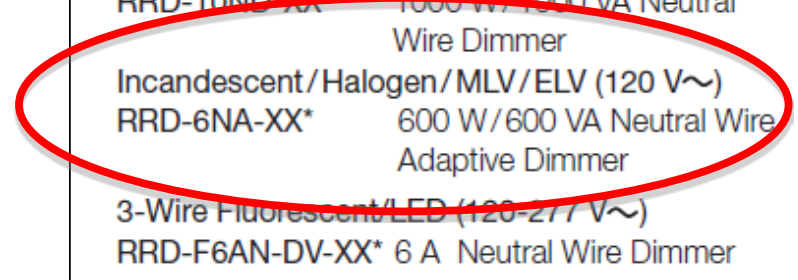

\section{Switches}

Lighting and Motor Loads (120 V )

RRD-8ANS-XX* 8 A Light, 1/4 HP 5.8 A Motor Neutral Wire Electronic Switch

Lighting and Motor Loads (120-277 V )

RRD-8S-DV-XX* 8 A Light, 1/10 HP 3 A Motor Two-Wire Electronic Switch

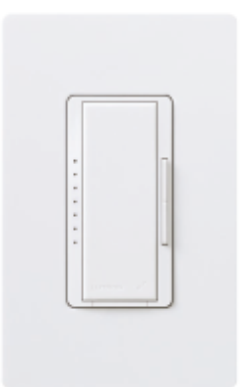

Dimmer

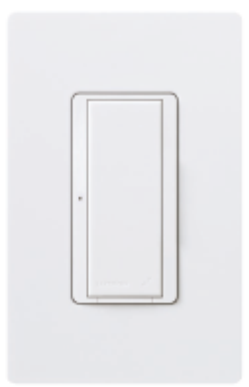

Switch

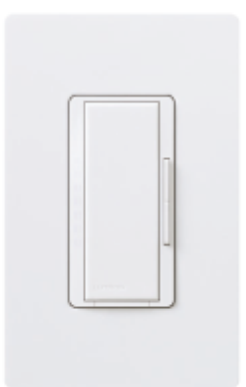

Remote Dimmer

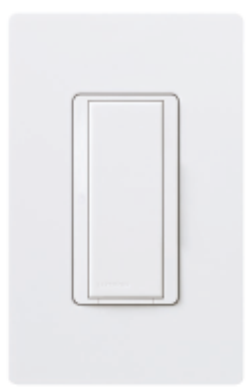

Remote Switch
Remotes (for multi-location installations) RD-RD- $X^{*} \quad$ Remote Dimmer (120 V ) RD-RS- $X^{\star} \quad$ Remote Switch (120 V ) RD-RD-277-XX* Remote Dimmer (277 V ) Use only with -F6AN-DV

RD-RS-277-XX* Remote Switch (277 V ) Use only with -8S-DV

\section{Color Change Kits}

RK-D-XX* Dimmers (-6D, -10D, -10ND, $-6 \mathrm{NA}$, and -F6AN-DV)

RK-S- $X X^{*} \quad$ Switches (-8ANS and -8S-DV)

RK-AD- $X X^{*} \quad$ Remote Dimmers (-RD)

RK-AS-XX* Remote Switches (-RS)

*RadioRA 2 Maestro local controls are available in 26 colors. Please see page 10 for color selections.

www.lutron.com/radiora2

Lutron@ | 1

Figure F.4. Lutron Radio Ra series wall-box dimmer with ability to adapt to different load types. 


\section{Appendix G: Hudson River valley church dimming documents}

\begin{tabular}{|c|c|c|c|c|c|}
\hline $\begin{array}{l}\text { Fixt } \\
\text { Type }\end{array}$ & Description & Lamps & Watts & Volt. & $\begin{array}{c}\text { Manufacturer's } \\
\text { Catalog }\end{array}$ \\
\hline D1 & $\begin{array}{l}\text { 6" square recessed downlight with } \\
\text { Par38 halogen lamp. Bronze } \\
\text { aluminum aperture cone. Lamp } \\
\text { face is regressed at least } 4 " \text { from } \\
\text { ceiling. }\end{array}$ & $\begin{array}{l}(1) \\
100 \mathrm{PAR} / \mathrm{HIR} / \mathrm{FL} \\
40\end{array}$ & Allow 120 & & Kurt-Versen H8634-SZ \\
\hline T1 & $\begin{array}{l}10 ' \text { long light track, or } 20^{\prime} \text { long track } \\
\text { composed of two } 10^{\prime} \text { sections with } \\
\text { center connector. Provide MR16 } \\
\text { track heads with integrated } \\
\text { honeycomb louver, number as } \\
\text { shown in plan. Painted finish to } \\
\text { match beam. Track is mounted to } \\
\text { vertical face of beams, } 6 " \text { above the } \\
\text { bottom of the beam, unless } \\
\text { otherwise noted. }\end{array}$ & $\begin{array}{l}\text { (1)Q50MR16/C/ } \\
\text { FL40 per track } \\
\text { head }\end{array}$ & $\begin{array}{c}\text { Assume } \\
100 \mathrm{~W} \text { per } \\
10 \text { ' length of } \\
\text { track }\end{array}$ & 120 & $\begin{array}{l}\text { Lighting Services Inc } \\
\text { (1)31XXO-Custom Paint } \\
\text { TBD (Track) Feed and } \\
\text { connectors as required. } \\
\text { LN16-00+Honeycomb } \\
\text { louver-Custom Paint (MR } \\
16 \text { head) }\end{array}$ \\
\hline T5 & $\begin{array}{l}\text { 8" Horizontally-mounted 1-circuit } \\
\text { surface-mounted track with halogen } \\
\text { Par38 track heads as shown in } \\
\text { plan. Track to be mounted on } \\
\text { ceiling, centered 4" from the beam. } \\
\text { Painted in black. Provide } \\
\text { HONEYCOMB louver accessory, } \\
\text { not cube-cell louver. }\end{array}$ & $\begin{array}{l}\text { (1)60PAR/HIR/F } \\
\text { L40 per track } \\
\text { head }\end{array}$ & $\begin{array}{c}\text { Assume } \\
800 \text { per } \\
\text { track length. }\end{array}$ & 120 & $\begin{array}{l}\text { Lighting Services Inc } \\
\text { (1)312XX-(Black track) } \\
\text { Feed and connectors as } \\
\text { required 238-00- } \\
\text { Honeycomb louver-black } \\
\text { (PAR38 head) }\end{array}$ \\
\hline
\end{tabular}

Figure G.1. A selection from the church luminaire schedule, from the time of the church renovation in 2008. 


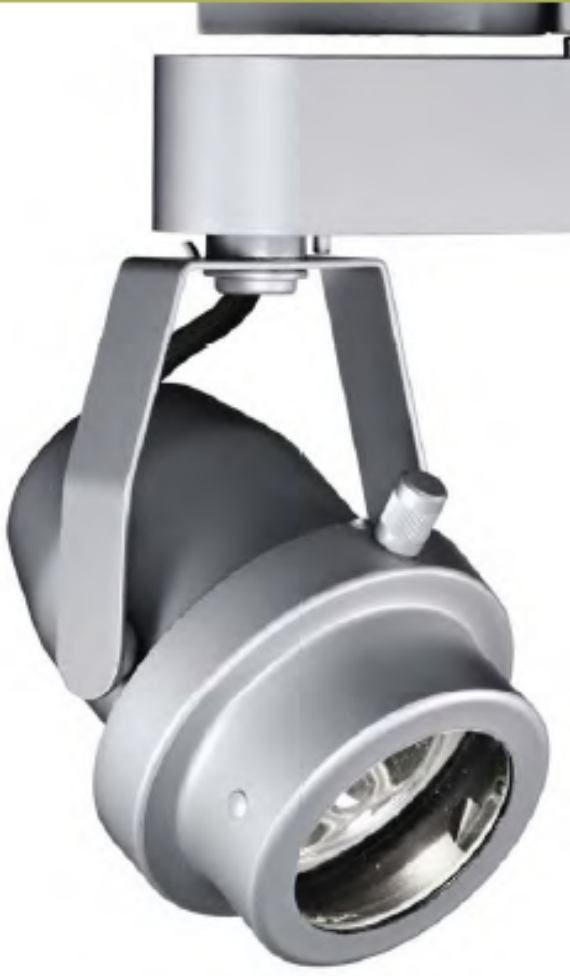

This versatile, miniaturized fixture revolves around two separate axes and pans vertically on a third axis for optimal and precise target illumination.

\footnotetext{
- Designed for Tungsten Halogen 2-pin base MR16 lamps up to 75 watts

- Can be configured for use on $120 \mathrm{~V}$ or $277 \mathrm{~V}$ systems

- Sturdy aluminum housing

- Self-locking swivel for horizontal and vertical focusing

- On/off safety switch (on most mounting types)

- Hinged front with relamping handle ensures easy lamp changing

- Internal multiple accessory clips accept any double combination of size-AAA LSI filters and accessories

- Optional crossbaffle hood eliminates frontal spill light and glare

- Revolving aluminum transformer housing with Integral 75VA $120 \mathrm{~V} / 11.6 \mathrm{~V}$ or $277 / 11.6 \mathrm{~V}$ electronic transformer

- Integral clear Pyrex safety shield

- Finishes: LSI Black, White, Silver and Graphite

- Fixture weight: 1.5 lbs.
}

\section{MOUNTING OPTIONS}

\section{6-00}

Lexan Fitting for 1 and 2

circuit LSI Tradk. With OrVOff switch.

\section{6-BUS}

Lexan fitting for 1 and 2 circuit LSI

Busway. With On/Off switch.

\section{6-2G}

Universal fitting for Unistrut Systems and any screw or bolt-up applications. With switch, and 6-foot 3-wire aroundina cord and NEMA 5-15P olua.

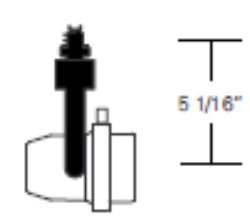

216-3G

C-clamp for pipes from $5 / 8^{*}$ to $2^{*}$ O.D. With switch, 6-foot 3 wire grounding cord and NEMA 5-15P plug.

\section{6-5A}

Canopy for permanent mounting on standard $4^{\text {" }}$ octagonal outlet boxes.
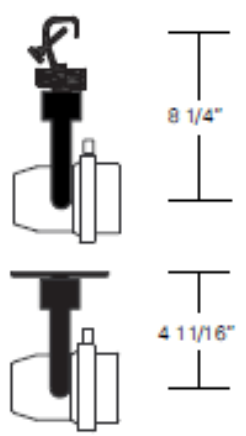

Other Options (Consult Factorvl:

Figure G.2. Lighting Services, Inc. MR16 track head with integral electronic transformer, installed in Hudson River Valley Church. 


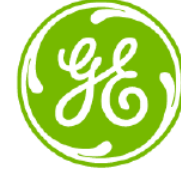

\section{Lighting}

69950 - LED7XDMR16D830/35

GE Energy Smart $\circledast$ MR16 Gen 2

- Energy-efficient LED lamps. Long life.

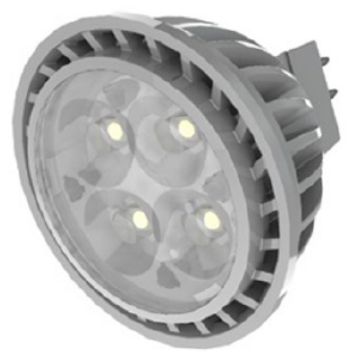

\begin{tabular}{|c|c|}
\hline GENERAL CHARACTE & ERISTICS \\
\hline Lamp Type & $\begin{array}{l}\text { Replacement Lamps - } \\
\text { Directional }\end{array}$ \\
\hline Bulb & MR16 \\
\hline Base & 2-Pin (GU5.3) \\
\hline Bulb Shape & MR16 \\
\hline Color & Silver \\
\hline Dimming Capability & $\begin{array}{l}\text { Operates on dimming circuits. } \\
\text { See GELighting.com/dimming } \\
\text { for further information }\end{array}$ \\
\hline Equivalent Wattage & $50.0 \mathrm{~W}$ \\
\hline Lamp Type & LED-MR \\
\hline Life in Years & 22.8 \\
\hline Rated Life & $25000.0 \mathrm{hrs}$ \\
\hline PHOTOMETRIC CHARA & ACTERISTICS \\
\hline $\begin{array}{l}\text { Beam Spread } \\
\text { Center Beam Candlepower } \\
(\mathrm{CBCP})\end{array}$ & $\begin{array}{l}35.0^{\circ} \\
1500.0^{\circ}\end{array}$ \\
\hline $\begin{array}{l}\text { Color Rendering Index } \\
\text { (CRI) }\end{array}$ & 82.0 \\
\hline Color Temperature & $3000.0 \mathrm{~K}$ \\
\hline Initial Lumens & 500.0 \\
\hline Nominal Initial Lumens per & 71.42 \\
\hline ELECTRICAL CHARAC & CTERISTICS \\
\hline Voltage & 12.0 \\
\hline Wattage & 7.0 \\
\hline DIMENSIONS & \\
\hline Bulb Diameter (DIA) & $2.000 \mathrm{in}(50.8 \mathrm{~mm})$ \\
\hline $\begin{array}{l}\text { Maximum Overall Length } \\
\text { (MOL) }\end{array}$ & $1.8800 \mathrm{in}(47.8 \mathrm{~mm})$ \\
\hline PRODUCT INFORMATIC & ION \\
\hline Product Code & 69950 \\
\hline Description & LED7XDMR16D830/35 \\
\hline Standard Package & Case \\
\hline Standard Package GTIN & 10043168699508 \\
\hline Standard Package Quantity & 6 \\
\hline Sales Unit & Unit \\
\hline No Of Items Per Sales Unit & 6 \\
\hline $\begin{array}{l}\text { No Of Items Per Standard } \\
\text { Package }\end{array}$ & 6 \\
\hline UPC & 043168699501 \\
\hline
\end{tabular}

Figure G.3. GE 7W LED MR16 lamp data.

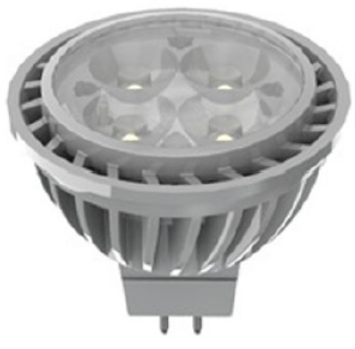

\section{Directiona}

2-Pin (GU5.3)

MR16

Operates on dimming circuits. See GELighting.com/dimming $50.0 \mathrm{~W}$

LED-MR

22.8

CTERISTICS

Center Beam Candlepower 1500.0

Color Rer

$$
\text { (CRI) }
$$$$
\text { Initial Lumens }
$$

Nominal Initial Lumens per 71.42 


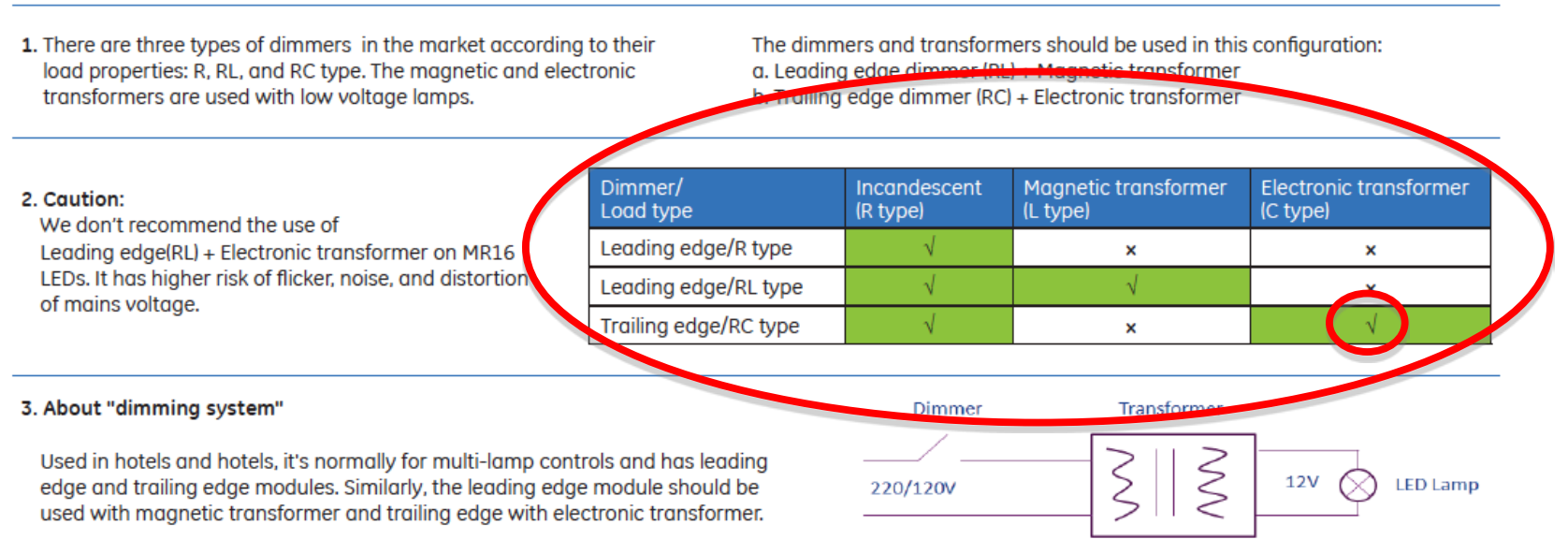

Figure G.4. GE 7W LED MR16 dimmer compatibility guidance, showing the trailing edge (reverse phase, ELV) dimmer is likely to work best with this LED lamp installed in an electronic transformer track head. (Source: http://www.gelighting.com/LightingWeb/na/images/ledreplacement-lamps-dimmer-compatibility-table.pdf.) 


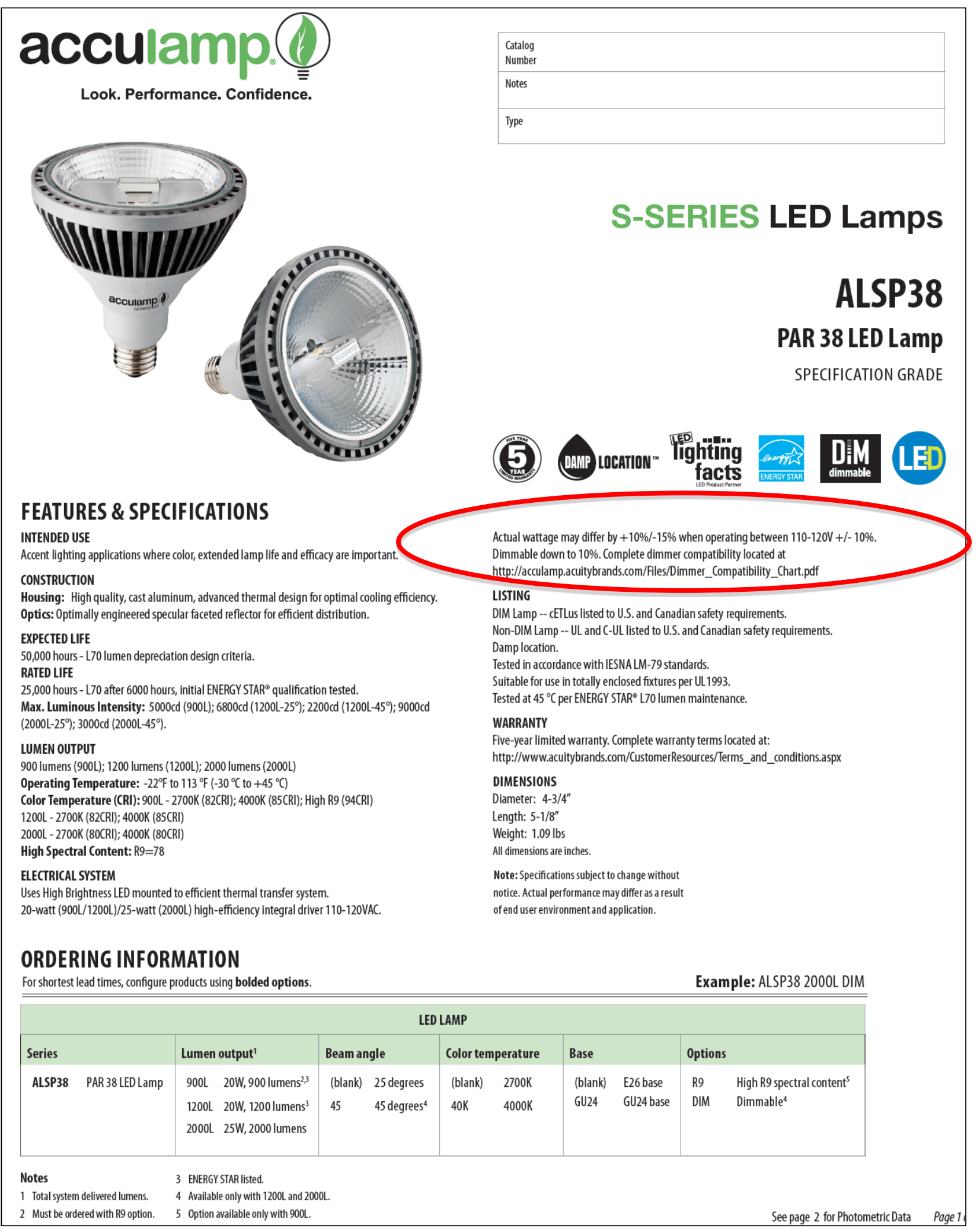

Figure G.5. Acculamp PAR38 LED lamp cut sheet. 


\section{LED DIMMER COMPATIBILITY CHART}

Look. Performance. C

LED LAMP AND DIMMER COMPATIBILITY 2-19-2013

LAMP: acculamp ${ }^{\ominus}$ ALSP38 1200 L DIM PAR38 20W DIMMABLE VERSIONS

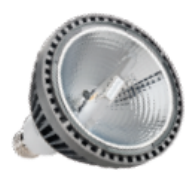

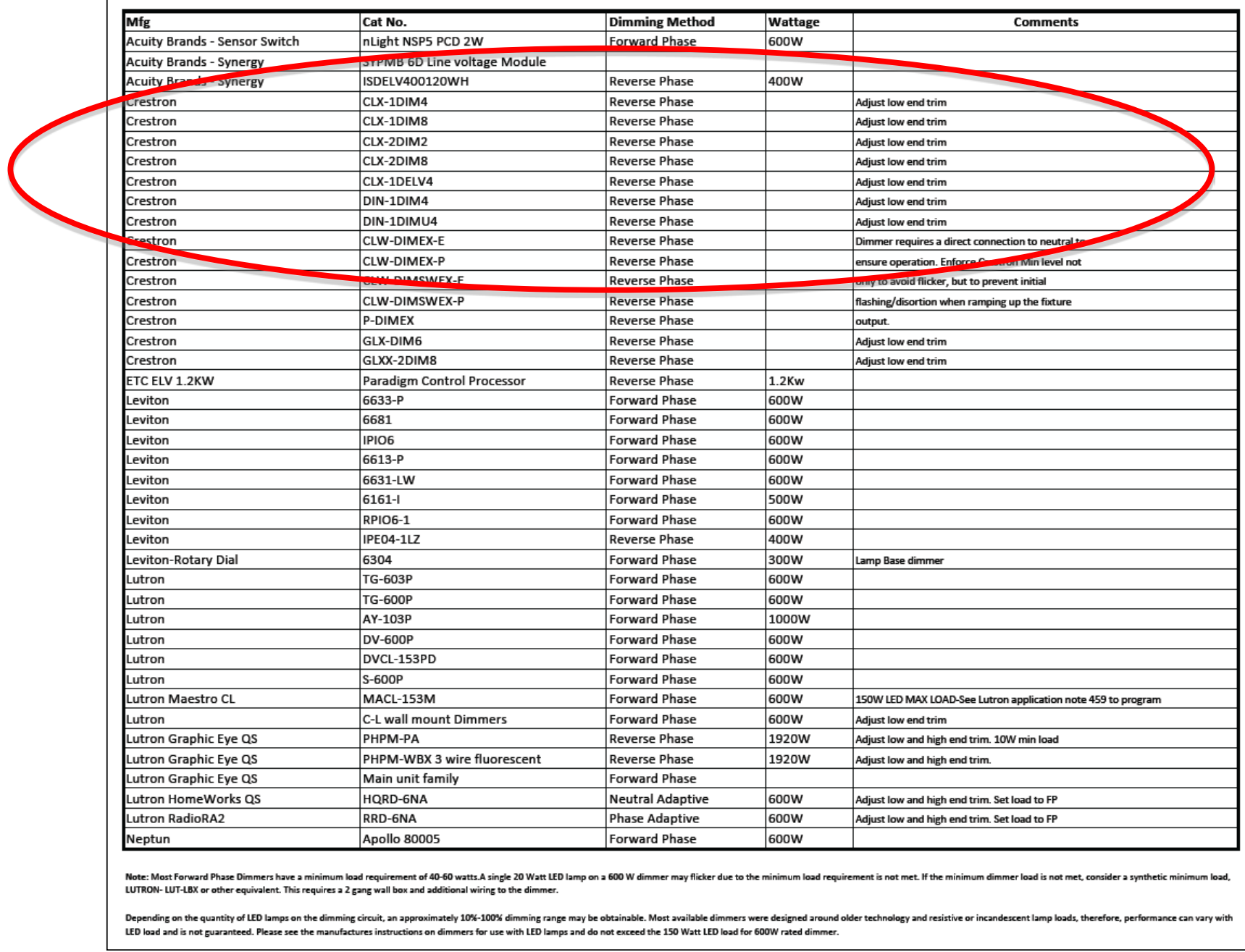

Figure G.6. Acculamp dimmer compatibility chart, recommending a reverse phase-cut dimming approach for its PAR38 LED lamp. 


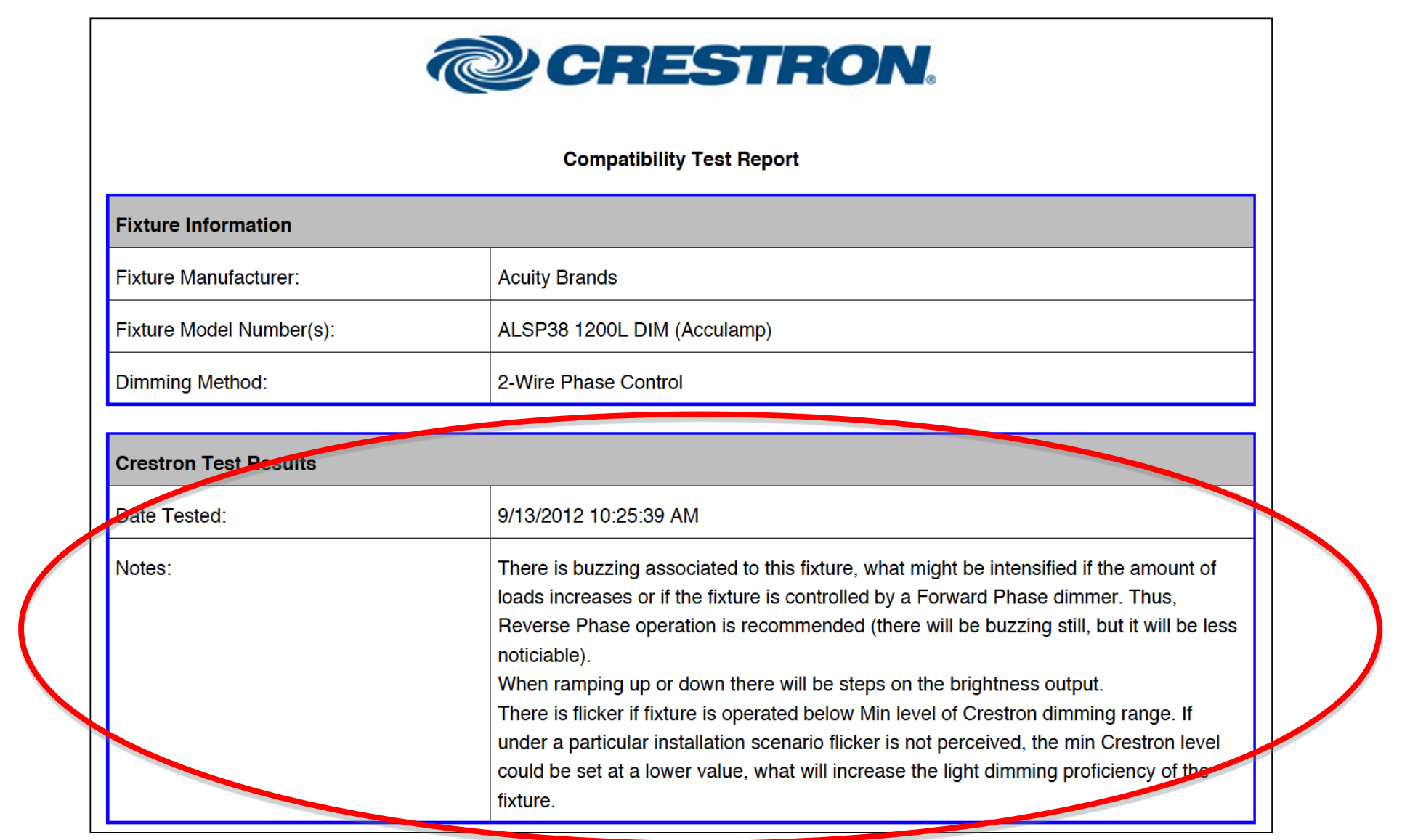

Figure G.7. Crestron's compatibility test report for the Acculamp PAR38 lamp recommends a reverse phase dimmer control for this lamp. (Source: http://www.crestron.com/downloads/pdf/ lighting_fixture_test_results/1086.pdf.) 


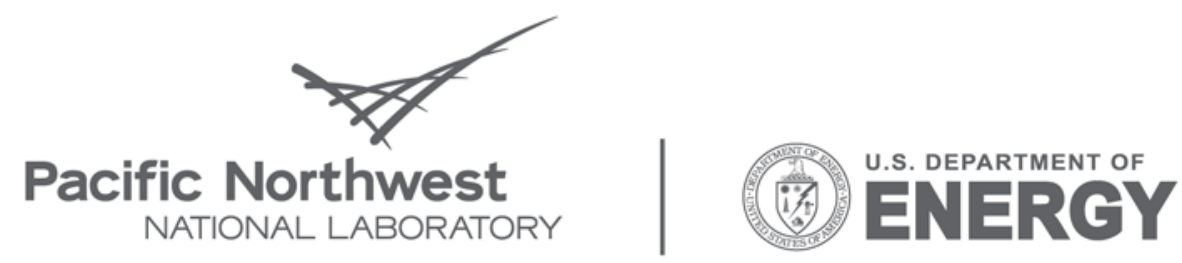

Proudly Operated by Battelle Since 1965

902 Battelle Boulevard

P.O. Box 999

Richland, WA 99352

1-888-375-PNNL (7665)

www.pnl.gov 